\title{
Cloud Cover over the Sahara during the Summer and Associated Circulation Features
}

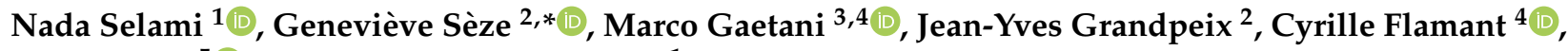 \\ Juan Cuesta ${ }^{5}(-)$ and Noureddine Benabadji ${ }^{1}$
}

1 LAAR, Genie Physical Department, Faculty of Physics, University of Science and Technology Mohamed Boudiaf, Oran BP 1505, Algeria; nada.selami@univ-usto.dz (N.S.); noureddine.benabadji@univ-usto.dz (N.B.)

2 LMD/IPSL, Sorbonne Universités, CNRS, EP, ENS, CEDEX 05, F 75252 Paris, France; jean-yves.grandpeix@lmd.ipsl.fr

3 Classe di Scienze Tecnologie e Società, Scuola Universitaria Superiore IUSS, 27100 Pavia, Italy; marco.gaetani@iusspavia.it

4 LATMOS/IPSL, Sorbonne Universités, UVSQ, CNRS, CEDEX 05, F 75252 Paris, France; cyrille.flamant@latmos.ipsl.fr

5 LISA/IPSL, UMR 7583 CNRS, Université Paris Est Créteil, Université de Paris, CEDEX, 94010 Créteil, France; cuesta@lisa.ipsl.fr

* Correspondence: genevieve.seze@lmd.ipsl.fr

Citation: Selami, N.; Sèze, G.; Gaetani, M.; Grandpeix, J.-Y.;

Flamant, C.; Cuesta, J.; Benabadji, N. Cloud Cover over the Sahara during the Summer and Associated Circulation Features. Atmosphere 2021, 12, 428. https://doi.org/ $10.3390 /$ atmos 12040428

Academic Editor: George Kallos

Received: 11 February 2021

Accepted: 22 March 2021

Published: 26 March 2021

Publisher's Note: MDPI stays neutral with regard to jurisdictional claims in published maps and institutional affiliations.

Copyright: (c) 2021 by the authors. Licensee MDPI, Basel, Switzerland. This article is an open access article distributed under the terms and conditions of the Creative Commons Attribution (CC BY) license (https:// creativecommons.org/licenses/by/ $4.0 /)$.

\begin{abstract}
Over the Sahara in summer, the activity of the Saharan thermal low pressure system (SHL), which is linked to the West-African monsoon dynamics and the mid-latitude circulation, is modulated by dust concentration and water-vapor transport. In this context, the role of clouds over western Sahara remains under-investigated. Using Meteosat-Second-Generation geostationary satellite data, for the first time the variability of cloud occurrence over Sahara by type in summer, at diurnal, daily and intra-seasonal time scales for the 2008-2014 period is documented. Using European Center for Medium-range Weather Forecasting (ECMWF) Reanalysis (ERA) Interim (ERAI) reanalysis, cloud cover occurrences are characterized in terms of regional circulation patterns and moisture balance. We show that, over West-Sahara and Hoggar, mid-top clouds are the most frequent cloud-type in summer. Their summit reaches between $500 \mathrm{hPa}$ and $400 \mathrm{hPa}$ and lies just above the top of the Saharan Atmospheric Boundary Layer (SABL). During the rest of the year, high-top clouds are the most frequent. The variations in the spatial distribution of mid-top cloud occurrence coincide with the seasonal displacement and strengthening of the SHL and, in the mid-troposphere, of the Saharan anticyclone. Mid-top clouds occur most frequently when, at large scale, mass and humidity converge in the lower SABL due to heating on an extensive surface, and diverge in the upper SABL. Their diurnal cycle, with minimal frequency around 10 UTC and maximum in the evening, is consistent with the diurnal development of the Saharan Convective-Boundary-Layer. The frequency of high cloud increases when anticyclonic circulations at mid-level and upper-level retreat to the southeast and upper-level trough from mid-latitudes can penetrate more southwards.
\end{abstract}

Keywords: mid-level clouds; Saharan boundary layer; heat low; climatology; satellite observations; moisture convergence

\section{Introduction}

Atmospheric dynamics in the Sahara region is a key element of the climate system, interconnected with the Atlantic to the west, the Mediterranean to the north and the Sahel and tropical West Africa to the south. In summer, the atmospheric circulation in this region is particularly complex. On the one hand, mass and moisture flows from surrounding regions modulate the local thermodynamics [1,2]. On the other hand, atmospheric dynamics in the Sahara impacts climate and synoptic variability at the regional scale as a major component of the West African Monsoon [3-5]. Above northern Africa, the circulation in the upper troposphere is dominated by the western portion of the Tibetan high, associated with the 
Indian monsoon deep convection [6]. The main axes of the resulting anticyclonic circulation are the sub-tropical westerly jet (STWJ), flowing along the North African coast, and the tropical easterly jet (TEJ), located above equatorial Africa [6]. In the mid troposphere, the Sahara is dominated by an anticyclonic circulation associated with the subsidence of the descending branch of the meridional Hadley circulation, and maintained by the radiative cooling in the upper troposphere [6]. The lower troposphere is dominated by the Saharan heat low (SHL), a near surface thermal low pressure developing over western Sahara in response to the radiative warming of the surface [4]. The cyclonic circulation associated with the thermal low drives the moisture transport from the subtropical North Atlantic and the Mediterranean across the desert [2,5].

The Sahara is the world's largest dust source [7]. In summer in its western part, the Sahara is characterized by the deepest atmospheric boundary layer (the so-called Saharan atmospheric boundary layer-SABL) on Earth when the SHL, in its north-westward migration, reaches this region [4]. In the SABL, aerosols and water vapor are mixed and processed up to 6-7 $\mathrm{km}$ in the troposphere, with clouds often formed on its top [8-11]. The physical mechanisms controlling the complex interactions among aerosols, water vapor and clouds, are still far from being completely understood, casting uncertainty on the modeling of the radiative budget and atmospheric dynamics in this region [12]. This incompleteness is a crucial limitation for climate modeling and predictability at regional and global scale, demanding substantial improvements [13]. Cloud cover distribution especially above the Sahara and the mechanisms leading to its formation are barely reported in the literature. During the JET2000 campaign [14], Parker et al. [8] identified from aircraft measurements a high level of relative humidity in the upper part of the SAL (Saharan Air Layer) and observed clouds at this level. Then in the framework of AMMA (Analyses multidisciplinaires de la mousson africaine) project [15] and Fennec [16] field campaigns, several papers were published including observations of clouds over the western Sahara. For example, observations of clouds and their diurnal cycle have been described by Cuesta et al. [9], who collected light detection and ranging (lidar) data on the ground at the Tamanrasset weather station in the Hoggar massif (Figure 1) during AMMA in 2006. In summer, in the afternoon, simultaneous to the growth of a convective boundary layer, lidar data show the development of clouds at the top of the SABL lasting until evening and even late evening during periods of strong dry convection. Marsham et al. [17], from measurements over western-central Sahara at the Bordj Badji Mokhtar Supersite-1 (Figure 1) during the Fennec experiment in June 2011 show that the cloud cover reaches its maximum between 18 UTC and 21 UTC whilst the SABL top height decreases after 18 UTC but the moistening above increases until 21 UTC. Another finding is that dusty days tend to also be cloudy. Kealy et al. [18] also describe cloud located at the top of the SABL and the broken aspect of this cloud cover from airborne lidar and radiometer data collected during the Fennec experiment. Comparing this data set with MET Office retrievals from MeteosatSecond-Generation geostationary satellite data, Kealy et al. [18] suggest the possibility of cloud cover overestimation due to the fragmentation of this cloud cover associated with the frequent occurrence of dust uplift. Stein et al. [19], Bouniol et al. [20] and Bourgeois et al. [21] analyzing the daily data (around 01.30 and 13.30, equator-crossing local time) from the space-borne lidar CALIOP and radar CLOUDSAT over West Africa, show that clouds in summer over western Sahara are placed at the top of the SABL $(\sim 500 \mathrm{hPa})$. These clouds occur more frequently during nighttime than daytime. All these studies are limited however in both space and time coverage and do not allow a complete description of the cloud cover distribution over the Sahara in summer. 


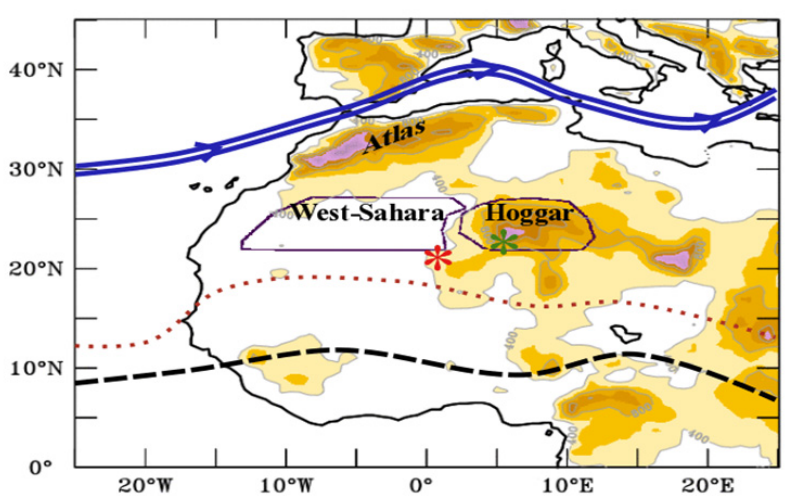

Figure 1. Map of West Africa with relief, July position of sub-tropical westerly jet (STWJ, blue line) [22], maximum monthly mean rainfall (dashed black line) [22], northernmost position of monthly mean rainfall $>25 \mathrm{~mm}$ (dotted red line) [22], the contours of the West-Sahara and Hoggar regions (garnet), the Tamanrasset meteorological station (green star) and the supersite- 1 of Bordj Badji Mokhtar during the Fennec experiment (red star). For the altitude, the isolines are given every $200 \mathrm{~m}$ from $400 \mathrm{~m}$. Altitude above $1200 \mathrm{~m}$ (light purple).

The objectives of this paper are to provide a more complete description of the cloud cover distribution in the region of the central western Sahara and the Hoggar massif, where the SHL builds up in summer, and to characterize the cloud cover occurrence in relationship with circulation patterns and moisture convergence over this region. With this aim in mind, a climatology of cloud type occurrence during boreal summer (June to September, JJAS) from 2008 to 2014 has been built. This is the first quantification of cloud occurrence by type over the Sahara during summer and of its spatial distribution, from diurnal to intra-seasonal scales. To do that, SAFNWC (Satellite Application Facility for Nowcasting) cloud observations at high temporal and spatial resolution obtained from Meteosat Second Generation (MSG) geostationary satellites are used. Atmospheric variables from the European Center for Medium-range Weather Forecasting (ECMWF) Reanalysis (ERA) Interim product are used to identify the circulation and moisture convergence patterns over this region which are linked to different cloud cover types. Analyses are conducted separately for the central western Sahara (hereafter called the West-Sahara) where the SHL is established in July and August [4] and for the mountainous Hoggar area (hereafter referred to as Hoggar) to the east and south of which the SHL is located in June before the monsoon onset $[4,9,23]$. Their boundaries are shown in Figure 1 . To simplify the analysis, the West-Sahara does not include the coastal region which is subject to a stationary sea breeze front during the day which penetrates the land during the night [24,25].

The paper is organized as follows. Satellite retrievals and reanalysis products are presented in Section 2, along with a description of the cloud type classification method. In Section 3, the main climatological features of cloud cover over West Africa are presented followed by a more precise description of the cloud cover occurrence over the West-Sahara and Hoggar. At the same time, the main elements of the atmospheric circulation over the Sahara and Sahel are given in summer. In Section 4, cloud cover occurrence is characterized over the West-Sahara and Hoggar in terms of the regional circulation patterns and moisture balance. Section 5 first provides a seasonal scenario of large-scale conditions and of the development of a deep SABL over the Sahara and mid-top cloud cover occurrence, and then discusses the main characteristics of the SABL and its diurnal cycle and the possible impact of a change in these characteristics on the occurrence of mid-top clouds. A summary and conclusion are provided in Section 6. 


\section{Data}

2.1. Spinning Enhanced Visible and Infrared Imager (SEVIRI) Data and the Satellite Application Facility for Now-Casting (SAFNWC) Cloud Algorithm

The SEVIRI (Spinning Enhanced Visible and Infrared Imager), onboard the geostationary satellite MSG (METEOSAT second Generation, http:/ / www.eumetsat.int/website/ home/Satellites/index.htm (accessed on 23 March 2021)), is a visible and infrared multichannel imager which observes the Earth's atmosphere and surface at 13 different wavelengths: 3 visible channels, 2 near-infrared channels and 8 infrared channels. A very important feature of SEVIRI is its continuous imaging of the Earth, with a baseline repeat cycle of $15 \mathrm{~min}$. The imaging sampling distance is $3 \mathrm{~km} \times 3 \mathrm{~km}$ at nadir for standard channels, and down to $1 \mathrm{~km}$ for the high-resolution visible (HRV) channel.

Cloud types and cloud top pressure used in our studies are produced with the SAFNWC software (www.nwcsaf.org (accessed on 23 March 2021)) applied to SEVIRI data. The algorithm used in this software was developed within the framework of the Eumetsat Satellite Application Facility in support for Now Casting and very short range forecasting (NWC SAF). It is described in the Algorithm Theoretical Basis Document written by Derrien and Legleau [26]. Here is a summary of the main features of this algorithm which is applied to each pixel and performed in three steps: (1) cloud detection, (2) cloud type classification, (3) cloud to pressure determination. For the first step, one can find more concise information on the algorithm in Derrien and Le Gleau [27,28].

In step 1, to separate clear pixels from cloudy pixels, a series of threshold tests are applied sequentially [26-28]: tests on window channel brightness temperatures (BT at $10.8 \mu \mathrm{m}$ ) and bi-directional reflectance (at $0.6 \mu \mathrm{m}$ or $0.8 \mu \mathrm{m}$ ) but also differences of brightness temperature between two wavelengths (chosen among $10.8 \mu \mathrm{m}, 12 \mu \mathrm{m}, 3.9 \mu \mathrm{m}$, $8.7 \mu \mathrm{m})$, on spatial and temporal variability of BT at $10.8 \mu \mathrm{m}$ and spatial variability of bi-directional reflectance. The set of thresholds to be applied depends mainly on the illumination conditions (nighttime, twilight, daytime). With the exception of the spatial and temporal variability tests, the values of the thresholds themselves depend on ancillary data such as the illumination, the viewing geometry, the geographical location and numerical weather prediction model data giving the total column water vapor content and $925 \mathrm{hPa}$ air temperature, monthly SST (Sea Surface Temperature) climatology, and over land reflectance climatology. These values are computed from simulated clear sky BT and bi-directional reflectance simulated by the RTTOV (Radiative Transfer for TOVS) radiative transfer model [29] for thermal bands and the 5S radiative transfer model for the solar spectrum [30] for the atmospheric and surface conditions given by the ancillary data set.

In step 2, the method for assigning a cloud type to cloud pixels is based on the same approach as in step 1 (i.e., a set of threshold test on BT, differences on BT, and spatial variability of BT and reflectance). To the ancillary data set used in step 1 is added a coarse description of the temperature and humidity profiles using numerical weather prediction model profiles. This classification process, at the end of which 10 classes of clouds are defined, makes it possible to differentiate thick cloud from thin cloud or partial cloud cover. This cloud pixel partitioning is used in step three to choose the cloud height algorithm applied to each cloudy pixel.

In step 3, the cloud top height (CTH) for opaque clouds (clouds with IR emissivity close to 1$)$ is retrieved from the common IR $(10.8 \mu \mathrm{m})$ brightness temperature by considering them as black bodies. For low/mid-level clouds, tests are applied so as to place the CTH below the altitude of the temperature inversion where one exists. For thin clouds, a correction for semi-transparency is applied using two infrared (IR) channels, as in Schmetz et al. [31] and Menzel et al. [32]. For partial cloud cover, no cloud top pressure is given. For partial cloud class pixels, which correspond to very thin clouds, small cumulus, broken cloud cover [26,33], cloud edges, cloud top pressure retrieval is not possible [26].

The main limitations of the SAFNWC cloud algorithms are given in Derrien and Le Gleau [26] and an evaluations of the cloud products against CALIOP (Cloud-Aerosol Lidar 
with Orthogonal Polarization) space-borne lidar and CLOUDSAT space-borne radar data is given in Kerdraon and Le Gleau [34] (see also Seze et al. [33], Hamann et al. [35]).

\subsection{Cloud Top Pressure and Cloud-Type Classification over Sahara}

Initially, the eleven SAFNWC cloud types (clear sky, very low-top clouds, low-top clouds, mid-top clouds, thick high-top clouds, both thick and very high high-top clouds, thin semi-transparent clouds (cirrus), cirrus, thick cirrus, cirrus above another cloud layer, partial cloud cover), were grouped together to establish a classification according to the three main cloud types, low-top clouds, mid-top clouds and high-top clouds. However, the analysis of the repartition of cloud top pressure for each classes inside the whole cloud top pressure over Sahara show that part of thin cirrus could be in fact mid-top clouds. For this reason, it was decided to construct the classification into low-top clouds, mid-top clouds and high-top clouds using the SAFNWC cloud top product and two thresholds dividing the troposphere into three parts: lower troposphere, middle-troposphere and upper troposphere. $350 \mathrm{hPa}$ and $500 \mathrm{hPa}$ were retained as thresholds (see Appendix A).

For partial cloud cover for which no cloud top pressure is available, to assign a level to these SEVIRI partially cloudy pixels, the same approach as in Dommo et al. [36] is used: each pixel of the partial coverage class is reclassified as high-top, mid-top or low-top cloud depending on the distribution of these three cloud types in the vicinity of the pixel (see Appendix B).

Both the choice of the cloud top pressure thresholds and the results of the re-classification process of the SEVIRI partial cloud cover have been evaluated in a comparison with the CALIOP lidar data carried out using statistics and pixel-by-pixel comparisons (see Appendix C).

\subsection{European Center for Medium-Range Weather Forecasting (ECMWF) Reanalysis (ERA) Interim Data}

Cloud cover occurrence is characterized in terms of large scale circulation patterns and moisture budget in the region by using atmospheric variables extracted from the ERAInterim reanalysis (ERAI) dataset ([37], https: / /www.ecmwf.int/en/forecasts/datasets / reanalysis-datasets/era-interim (accessed on 23 March 2021)). For the 2008-2014 period, JJAS water vapor path, horizontal and vertical winds, temperature, specific humidity and geopotential height 6-hourly data, at $0.75^{\circ}$ latitude-longitude resolution (i.e., $80 \mathrm{~km}$ at the equator), on 37 vertical levels, in the domain $25^{\circ} \mathrm{W}-35^{\circ} \mathrm{E}$ and $0^{\circ} \mathrm{N}-45^{\circ} \mathrm{N}$, are used.

The SHL location is defined following Lavaysse et al. [4]. At each time step, the cumulative distribution of potential temperature at $850 \mathrm{hPa}$ is computed for the grid points within the $13^{\circ} \mathrm{W}-15^{\circ} \mathrm{E}$ and $15^{\circ} \mathrm{N}-35^{\circ} \mathrm{N}$ domain. The SHL location is defined as the area where the potential temperature exceeds the 97th percentile of the spatial distribution. In the following this potential temperature value will be called threshold. A map of the occurrence frequency of the SHL is then constructed for the entire period. In the frequency map, the area within the $15 \%$ isoline is chosen to represent the average location of the SHL. The same method is applied to the geopotential height at $600 \mathrm{hPa}$, to characterize the Saharan anticyclone (SAC), to the geopotential height at $100 \mathrm{hPa}$ and $200 \mathrm{hPa}$, to characterize the Tibetan anticyclone, and to the geopotential height at $900 \mathrm{hPa}$, to characterize the Azores anticyclone. The research domain, the frequency in the cumulative potential temperature or geopotential height distribution to select a threshold at each time step and the value of the final isoline in the frequency map to define the retained area are summarized in Table S1. The SHL and the SAC are determined at 18 UTC and 12 UTC, respectively, the times of their maximum intensity.

The latitude of the inter-tropical discontinuity (ITD) which separates the near-surface Saharan air from the cooler, moist monsoonal air [38-40] is defined here by an isodrosotherm in the $2 \mathrm{~m}$ dew point temperature field. Dew point temperature fields at $06 \mathrm{UTC}$ and the isodrotherm $15^{\circ} \mathrm{C}$ values [22,41] are used to take into account the northward movement of the monsoonal nocturnal flow $[38,40]$. However, caution should be exercised in interpreting the daily variations in the ITD. Moisture fluxes at the surface are not only related to the 
northward progression of the monsoon flow but also to sporadic strong northward rises in moisture fluxes carried by cold pools [42-45]. Moreover, these cold pools generated by deep convection systems which develop over the Sahel are not simulated properly in the ERAI product due to the convection parameterization scheme used [46,47].

In order to determine the levels at which water vapor is transported over the WestSahara and Hoggar regions, the horizontal convergence of water vapor in each layer, averaged over the domain for each 6-h time step, is calculated. If delta- $p$ is the layer thickness, gamma the domain contour, $d$-gamma the line element of gamma, and $n$ the inward normal to the contour, then the rate at which water vapor enters the domain in that layer reads, at each time-step:

$$
C=\frac{\operatorname{delta}_{p}}{g} \sum q * V . n * d_{g a m m a}
$$

where $q$ and $V$ are the specific humidity and the horizontal wind velocity at the contour point and $g$ the gravitational acceleration. The average convergence of water vapor in the domain of area $S$ and over a period is $\langle C\rangle / S$, where $\langle C\rangle$ is the time average of $C$. First, the four daily $C$ values were averaged to calculate the daily average water vapor convergence. For a longer period or for a selection of days, the average water vapor convergence is obtained by averaging the daily values.

The sum of the water vapor convergence should be equal to $\mathrm{dPW}+\mathrm{E}-\mathrm{P}$, where $\mathrm{dPW}$ is the change of the water vapor path between the beginning and the end of the period, $\mathrm{P}$ is the average precipitation and $\mathrm{E}$ the average evaporation over the surface of the domain. In the present case $\mathrm{E}-\mathrm{P}$ is very small so that the sum of the incoming fluxes should be equal to dPW, which is in itself small compared to the convergences. However, for the West-Sahara and Hoggar, the sums for the various months turn out to range between 0.22 and $0.87 \mathrm{~kg} / \mathrm{m}^{2} / \mathrm{d}$ for the West-Sahara and between 0.28 and $0.48 \mathrm{~kg} / \mathrm{m}^{2} / \mathrm{d}$ for Hoggar. These values are consistent with Meynadier et al. [48] who find a residual convergence ranging from 1.08 to $1.42 \mathrm{~kg} / \mathrm{m}^{2} / \mathrm{d}$ (see their Table A1) for three domains of West Africa located south of $20^{\circ} \mathrm{N}$; the larger values of the residuals of Meynadier et al. [48] may stem from the greater humidity in less dry locations. More frequent cold pools and the greater amount of moisture carried by these cold pools can contribute to these larger residuals.

One may expect the positive water budget residual to increase with the intensity of the water cycle in the troposphere. It so happens that the positive water budget residual is approximately proportional to the absolute value of the convergence in the [surface, $850 \mathrm{hPa}$ ] layer. For each time period in which the low-level convergence is always of the same sign, this leads to residuals in the order of $10 \%$ of the absolute value of the mean convergence. For periods during which the low-level convergence changes sign, the residuals may become proportionally greater.

These residuals provide uncertainty in the analysis of levels at which water enters the domain. However, these residuals will not harm the analysis especially in a day to day analysis.

\section{Cloud Cover and Cloud Cover Type Occurrence Observed with SEVIRI}

In this section, the general features of the summer (JJAS) cloud cover occurrence frequencies (COF) are first presented, for total cloud cover, high-top clouds, mid-top clouds and low-top clouds, over a region including Tropical North Africa, the Sahara, subtropical Northeast Atlantic and the Mediterranean. COF is defined in each SEVIRI pixel as the fraction of cloudy time steps over the total number of $15^{\prime}$ time steps over the 2008 to 2014 period. The main features of the atmospheric circulation, including the northward progression of lower troposphere humidity, the SHL and the SAC positions are also shown. A more detailed study of cloud cover occurrence over West-Sahara and Hoggar is then presented. 


\subsection{General Features of Cloud Cover Occurrence over West Africa \\ 3.1.1. Total and High-Top Cloud Cover}

Figure 2a,b show monthly average maps of total COF and high-top COF. Figure $2 \mathrm{~b}$ also gives the regions where maxima of geopotential height at $200 \mathrm{hPa}$ and $100 \mathrm{hPa}$ are the most frequently located (indicative of the Tibetan anti cyclone position; see Section 2 for the definition of these regions) and the boundary between the easterly and westerly winds at $200 \mathrm{hPa}$ (the zero isoline of $200 \mathrm{hPa}$ zonal wind). In Figure 2b, the northern boundary of the high-top cloud cover due to the ITCZ convective activity approaches $18^{\circ} \mathrm{N}$ during the pre-onset period in June and reaches $20^{\circ} \mathrm{N}$ during the monsoon peak in August [49]. This limit is close to the northern end of the precipitation belt (Figure 1) (Lélé et al. [50]). Linked to the ITCZ move, in the upper troposphere and mid-troposphere the easterly wind regime move also north (see the boundary between westerly and easterly wind in Figure $2 b$ ). In September, east of $10 \mathrm{~W}$, the northern limit of the high-top cloud cover returns to its June position, but west of $10 \mathrm{~W}$, this limit remains close to $20^{\circ} \mathrm{N}$. This may be related to the African Easterly Wave (AEW) regime, which peaks in September along the west coast of North Africa [51].
JUNE
JULY
AUGUST
SEPTEMBER

(a)
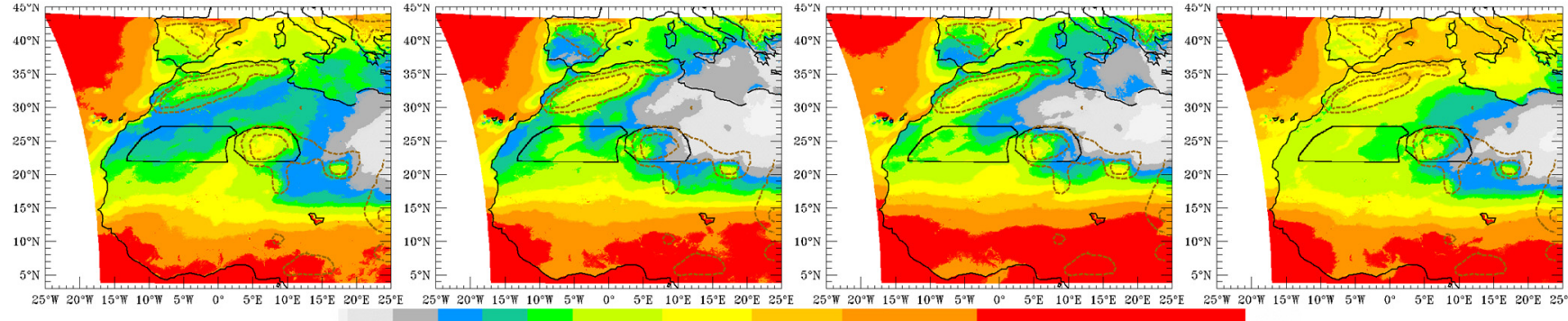

$05101520253035404550556065707580859055100 \%$

(b)

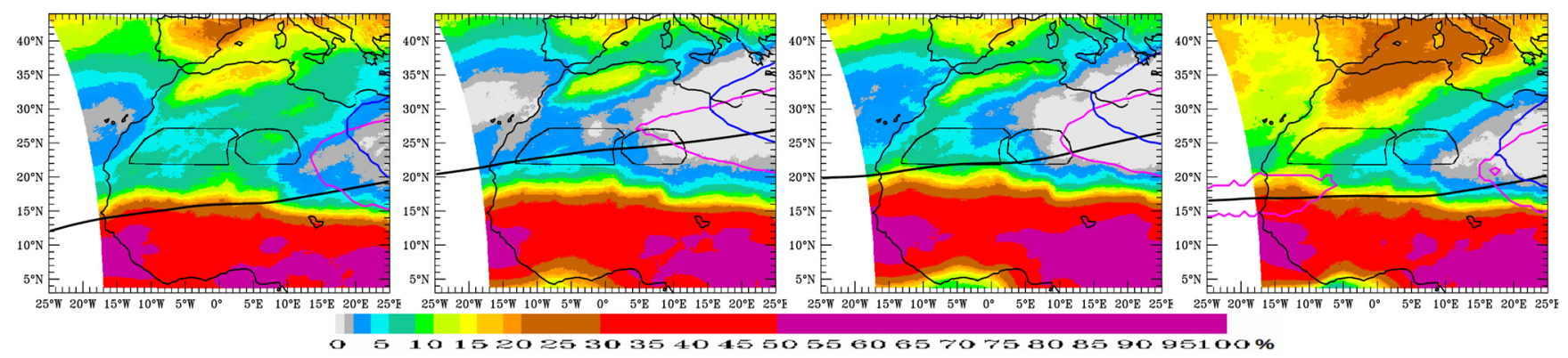

Figure 2. (a) Total cloud cover occurrence frequencies (COF, shadings), together with $650 \mathrm{~m}$ and $1000 \mathrm{~m}$ topography isolines (brown dashed contours). (b) High-top COF (shadings), zero isoline of the zonal wind at $200 \mathrm{hPa}$ (black), boundaries of the most frequent regions for the maximum of geopotential height at $200 \mathrm{hPa}$ and $100 \mathrm{hPa}$ (pink and blue contours, respectively).

Over the eastern Sahara where subsidence induced by the Tibetan high in the upper troposphere, is the strongest, clear sky is very frequent (large number of COF $<5 \%$ in Figure 2a-gray regions). Over western Sahara and Hoggar this frequency is not so large (COF $>10 \%$ ). From June to July, while the Tibetan high (region of maximum of geopotential height at $200 \mathrm{hPa}$ and $100 \mathrm{hpa}$ in Figure 2b) migrates northwestward and subsidence underneath reinforces [52], the clear sky frequency rises over Eastern Sahara but also over the eastern Hoggar massif. The northward shift of the anticyclone, contributes to the STWJ (Figure 1) moving northward and accentuates its tilt towards the northeast over eastern and central Mediterranean. In July, clear sky also predominates over the central and 
eastern Mediterranean (COF $<10 \%$ in Figure 2a). In August and September, over the central and eastern Mediterranean and the central and eastern Sahara, as the Tibetan anticyclone gradually retreats to the southeast, the frequency of clear skies diminishes.

In Figure 2b, from June to July, the upper cloud cover, relative to total cloud cover, reduces not only in eastern Sahara, but also in western Sahara and the eastern Atlantic. Over the eastern Atlantic, as the descending branch of the Hadley cell pushes the midlatitude flow northward, in the upper troposphere, clear sky frequencies above $95 \%$ become frequent (COF $<5 \%$ in Figure 2a). Over western Sahara, which is located between the two subsidence maxima related to the descending branch of the Hadley cell and to the Tibetan anticyclonic circulation, the frequency of high cloud does not reach the minimum values observed over eastern Sahara and the eastern Atlantic. In August, the high-top COF increases again over the East Atlantic and over the western Sahara. The STWJ begins to migrate southward and with the relaxation of the high pressure belt mid-latitude lows can penetrate farther south making the environment favorable for possible outbreaks of tropical moist air into the subtropical mid and high troposphere and occurrence of high clouds in these regions [53-55].

\subsubsection{Mid-Top Cloud Cover}

The monthly mean of mid-top cloud COF is given in Figure 3. In this figure is also given the regions where maxima of the SAC (geopotential at $600 \mathrm{hPa}$ ) at $12 \mathrm{UTC}$ and where the SHL at 18 UTC are the most frequently located.
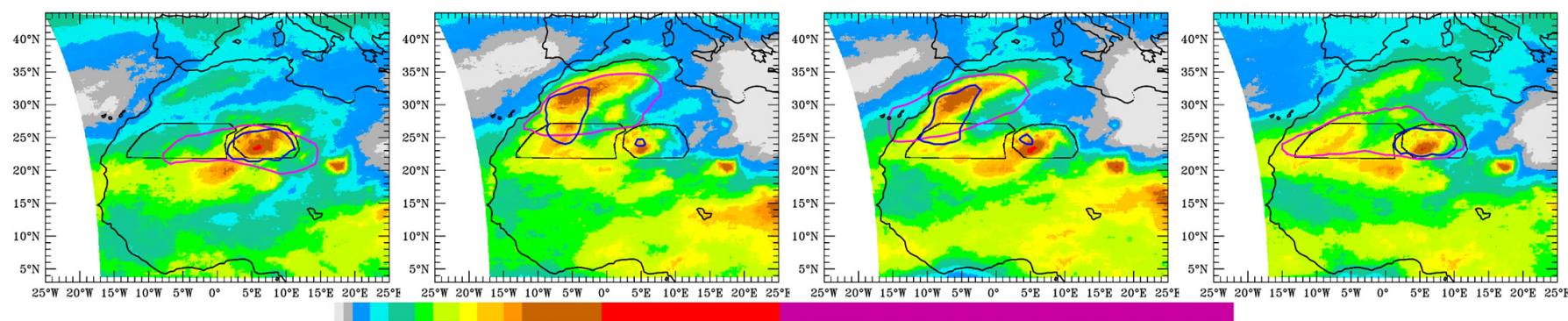

$05101520253035404550556065707580859095100 \%$

Figure 3. Mid-top COF (shadings), boundaries of the most frequent region for the Saharan anticyclone (SAC, pink contour) and most frequent region for the Saharan heat low (SHL, red contour).

Over the Sahara, west of $10^{\circ} \mathrm{E}$, in agreement with the previous studies on cloud cover over this region, Figure 3 shows the occurrence of clouds capped at mid-level. Compared however to these studies which described the meridional evolution of cloud cover profiles in a $10^{\circ} \mathrm{W}-10^{\circ} \mathrm{E}$ transect or with airplane or point measurements, Figure 3 shows that mid-top COF is not uniformly distributed over the region. For example, over the Hoggar the cloud cover can reach $40 \%$ in agreement with the cloud cover observed from synoptic surface observations at the Tamanrasset weather station (Figure 1) [9]. But the COF is below $20 \%$ between the Hoggar and the Atlas. Figure 3 shows also that the location of the maximum of COF differs from one month to the other. In June, the mid-top cloud cover is mostly concentrated over the Hoggar massif and over the Addrar massif to the South-West. During this period, the SHL (region of maximum potential temperature at $850 \mathrm{hPa}$ in Figure 3) is preferentially located south of the Hoggar. After the monsoon onset in July, the SHL strengthens, moves northwestward $[4,49]$ and reaches the foothills of the Atlas massif in August. The center of the Saharan anticyclone (region of maximum potential temperature at $850 \mathrm{hPa}$ in Figure 3) follows the SHL trajectory. From July, mid-top cloud cover occurs over the West-Sahara and the Atlas massif. In September both the SHL and the Saharan anticyclone move to the southeast. The mid-top cloud cover over the Atlas 
range decreases, replaced by a large amount of high-top cloud cover. However, mid-top cloud is the more frequent cloud type over the West-Sahara and Hoggar (Figure 3).

\subsubsection{Low-Top Cloud Cover}

Figure 4 shows the monthly mean of low-top cloud COF with superimposed the horizontal wind at $925 \mathrm{hPa}$, the ITD (the iso-drotherm $15^{\circ} \mathrm{C}$ in the $2 \mathrm{~m}$ dew point temperature field) and the regions where maxima of geopotential at $900 \mathrm{hPa}$ is located (Azores Anticyclone).

\section{JUNE}

JULY
AUGUST

SEPTEMBER

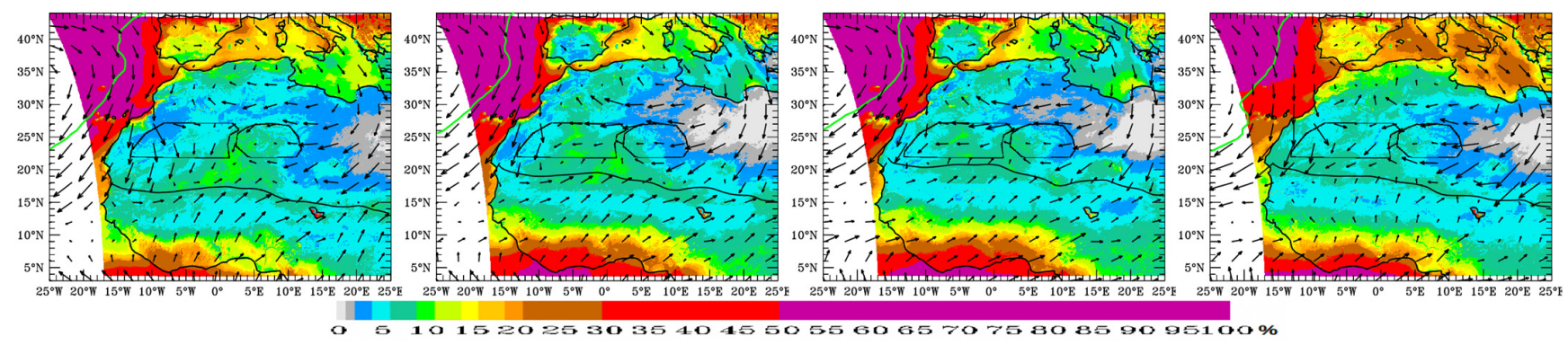

Figure 4. Low-top COF (shadings), inter-tropical discontinuity (ITD, black line), boundaries of the most frequent region for the geopotential at $900 \mathrm{hPa}$ (green line), horizontal wind at $925 \mathrm{hPa}$ (vectors).

Over southern West Africa, on the south part of the ITCZ (Figure 1), the low clouds are frequent in July and August, when the high-top clouds, which obscured the low cloud cover in June in the SEVIRI data, move northward. This illustrates the penetration of the monsoonal moisture flow $[19,20,50,56]$ from the ocean to the mainland, which feeds the deep convection within the ITCZ. Holle et al. [57] and Stein et al. [19], using cloud profiles obtained from combined lidar and radar data, determined that the frequency of low clouds was maximum just south of $7^{\circ}-8^{\circ} \mathrm{N}$. Here, with visible (VIS) and IR SEVIRI data, such behavior is not observable. From the equator northward, the frequency of low-top COF decreases (Figure 4) whilst the high-top COF increases (Figure 2b) indicating that low clouds occur more and more frequently under high-clouds when going northward until $7^{\circ}-8^{\circ} \mathrm{N}$. On the other hand, Van der Linden et al. [58] show that SAFNWC low-top COF close to the Guinean coast is underestimated during nighttime due to a poor separation with clear sky. On the northern boundary of the high cloud cover at $15^{\circ} \mathrm{N}$ (see Figure $2 \mathrm{~b}$ ) the frequency of low-top cloud (Figure 4) is low. This is in agreement with the observations of Parker et al. [8] during the JET2000 experience, showing the small occurrence of low-top cloud just north of the AEJ (African Easterly Jet). These observations are confirmed by the results of CALIOP/CLOUDSAT analysis of Stein et al. [19]. But the low-top COFs observed in Figure 4, although low, are higher than those given by the CALIOP climatology. Over the Sahara, the SEVIRI-derived low clouds are in fact most often detected as broken edges of mid-top clouds or as clear air in the CALIOP data set (see Appendix C). It can be noted that the northward progression of the ITD from June to August, as well as its withdrawal in September, coincides well with that of the high-top clouds (Figure 2b) over the same period.

\subsection{Intra-Seasonal Evolution of Cloud Cover over the Hoggar and the West-Sahara}

To specify the characteristics of the cloud cover over the Sahara and their evolution during the summer, the emphasis is on the two regions where the occurrence of mid-high clouds is the most frequent, but which do not show the same intra-seasonal evolution: the massif of the Hoggar and the region of the West-Sahara (Figure 1). For these two regions the total, mid-top and high-top COF are calculated at each $15^{\prime}$ time step and are then averaged throughout the day. T DCOF, H DCOF and M DCOF are the daily total, high-top and 
mid-top cloud occurrence frequencies, respectively. The low-top cloud class is renamed as very-partial cloud cover class (see Appendix C) and its occurrence frequency is calculated for both regions. VP DCOF is the daily very-partial cloud COF. Firstly, monthly average statistics, including cloud top pressure distribution and cloud frequencies diurnal cycle are analyzed. Then the evolution of the daily cloud frequency of high-top clouds and mid-top clouds (H DCOF and M DCOF) during the season and the peculiarities of these frequencies compared to the rest of the year are discussed.

\subsubsection{Monthly Mean Statistics}

Figure 5a shows the distribution of cloud top pressure over western Sahara and the Hoggar. In this distribution, the peak at $400 \mathrm{hPa}$ indicates that the cloud cover is preferably at this altitude which is close to but above the SABL top in agreement with observations from lidar data (see Appendix C and [9,10,18-21]). In July, when the frequency of high-top clouds is low (Figure $2 \mathrm{~b}$ ), the distributions are reduced almost to a single peak, whilst in June and September over the West-Sahara, a secondary peak appears at $275 \mathrm{hPa}$.

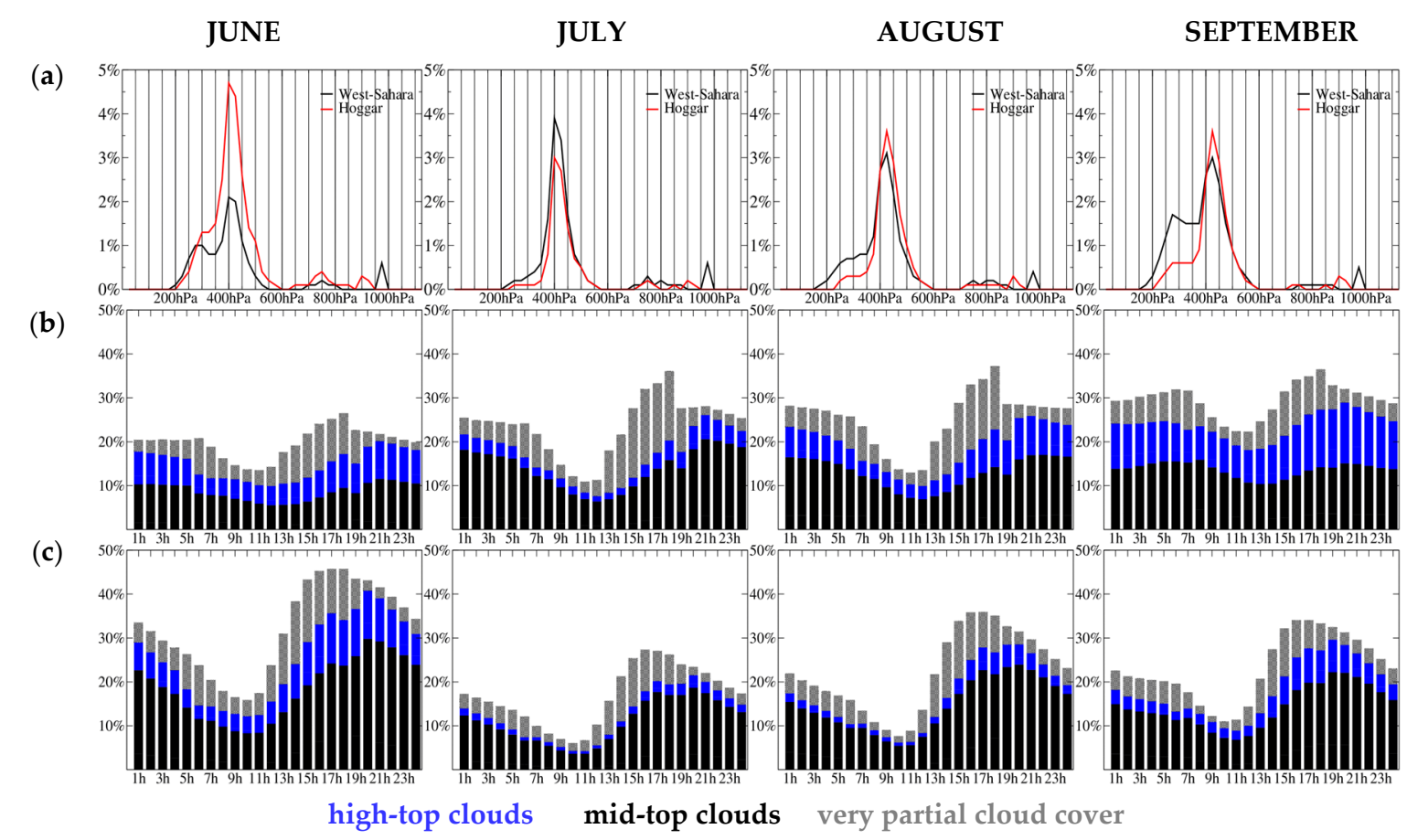

Figure 5. (a) Cloud top pressure occurrence frequency distributions for West-Sahara (black line) and Hoggar (red line). (b) for West-Sahara and (c) Hoggar, the diurnal evolution of the COF at 15' time step averaged over one hour.

To construct Figure 5a, pixels belonging to the very-partial cloud cover class were retained when a pressure level was available (i.e., pixels classified as low cloud in the SAFNWC classification prior to the partial cloud cover pixel reclassification process). This shows the very small contribution of these "false" low clouds if CALIOP is taken as reference (see Appendix C).

In Figure $5 b$ for the West-Sahara and Figure $5 c$ for the Hoggar, the diurnal cycle of the occurrence frequencies of mid-top and high-top cloud cover and very partial cloud cover is given. The diurnal cycle of mid-top cloud COF is characterized by a minimum during the morning and an increase during the afternoon to reach its maximum in the evening. It clearly agrees with the diurnal cycle of cloud cover observed with a ground-based lidar over the Hoggar in summer 2006 [9] and over the site of Bordj Badji Mokhtar (21.38 N, 0.92 E) (Figure 1) during the Fennec experiment in June 2011 [21]. In the climatology of cumulus diurnal cycle built by Eastman et al. [59] using synoptic surface observations from stations located between the Hoggar and the Atlas (Figure 1), cumulus occurrence 
peaks in the late afternoon (between 16 UTC and 21 UTC). Using the same synoptic surface observations climatology and for the 4 stations included in the Hoggar and West Sahara regions ( 2 in the Hoggar and 2 in the West-Sahara), it is found that the two most frequent cloud types are cumulus and alto-cumulus. The cumulus cloud occurrence peaks between 17 UTC and 18 UTC but that alto-cumulus occurrence peaks between 23 UTC and 02 UTC.

In the SEVIRI data, the very-partial cloud cover COF reaches a maximum in the afternoon when cloud must begin to form at the top of the boundary layer. This very partial cloud cover could correspond to what observers from the ground call cumulus clouds in this very arid region. The strong discontinuity in very partial cloud cover frequency at twilight above the West-Sahara is an artefact of the method. Over the Hoggar where the orography enhance convection process, in surface observations, cumulus clouds are the most frequent cloud type, while over West-Sahara, alto-cumulus clouds are more frequent. This is consistent with the decrease in mid-top cloud cover in the early hours of the night, whereas over West-Sahara, mid-top cloud cover persists until late into the night (04 UTC). It is also noted that the largest amplitudes in diurnal variations of mid-top clouds occurrence are over Hoggar.

\subsubsection{Intra-Seasonal and Seasonal Evolution of Daily Cloud Frequencies}

Figure 6a-c show the distributions of high-top DCOF, mid-top DCOF and VP DCOF built over 15 day periods for West-Sahara (left) and Hoggar (right)s. To highlight the particularities of the cloud cover during the JJAS period compared to the period from October to May, the whole annual cycle is given. The same pressure thresholds to differentiate between low-top, mid-top and high-top clouds were used for the October to May period than those used for the JJAS period even though the frequency of occurrence of a cloud type may be slightly under- or over-estimated (see Appendix C).

West-Sahara

(a)

(b)

(c)

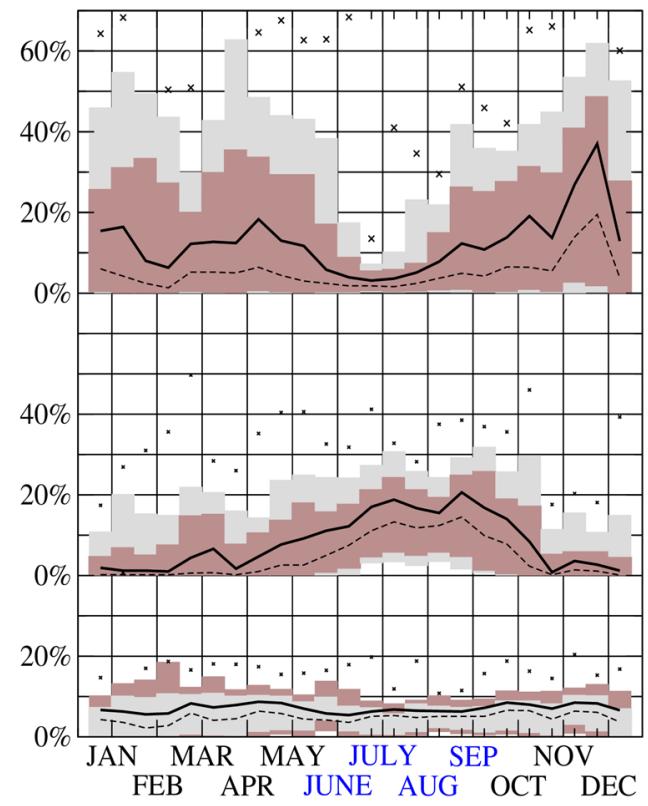

Hoggar

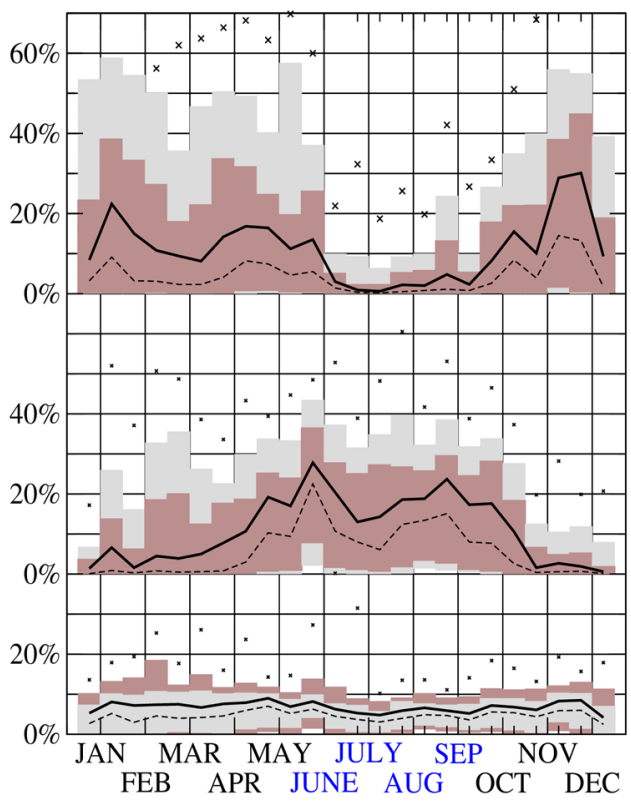

Figure 6. (a) annual cycle of the distributions of high-top daily cloud cover occurrence frequency (DCOF) distributions built over 15 day periods for West-Sahara (left) and Hoggar (right). (b,c) same as (a) but for mid-top DCOF and daily very-partial cloud cover occurrence frequency (VP DCOF), respectively. Each 15 day distribution has been partitioned in three parts, using the $5 \%$ percentile, $15 \%$ percentile, $85 \%$ percentile and $95 \%$ percentile. The brown areas span the part of the distribution within the 15th and 85th percentiles, the gray areas span the part of the distribution within the 5th and 95th percentiles. Dashed black lines indicate the 50th percentile, solid black lines indicate the 70th percentile, crosses indicate the maximum values. 
From June to September, mid-top cloud cover is the most frequent cloud type (Figure 6b; Table S2. During this period, more than $30 \%$ of the time the daily occurrence frequency of mid-top clouds (M DCOF) is above $10 \%$. In Figure $6 \mathrm{~b}$, in mid-May, M DCOF increases to dominate the cloud cover up to mid-October, whilst H DCOF decreases over the Hoggar and the West-Sahara, reaching its yearly minimum in mid-July (Figure 6a). In summer, VP DCOF almost never exceeds $10 \%$.

In the following, each day is classified from its frequency values T DCOF, M DCOF and H DCOF. Based on this classification a more in-depth analysis of the intra-seasonal evolution of the mid-top and high-top cloud cover occurrence during summer is performed. To build this classification, a 10\% threshold to select mid-top cloud days and high-top cloud days is used. A mid-top day is a day with tM DCOF above $10 \%$ and H DCOF below $10 \%$. A high-top day is a day with $\mathrm{H}$ DCOF above $10 \%$. Adding a constraint on $\mathrm{M}$ DCOF, a high-top day can be either a high-top-alone day when M DCOF is below $10 \%$ or a high-top-plus-mid-top day when M DCOF is above $10 \%$. Clear days are days where $\mathrm{M}$ DCOF is below $8 \%, \mathrm{H}$ DCOF is below $8 \%$ and T DCOF (the total cloud cover occurrence frequency) is below $18 \%$. The constraint on T DCOF value is added, in order to exclude days with a large fraction of very partial cloud cover pixels. From these criteria, $90 \%$ of the days are classified. The 10\% remaining will be not taken into account in the following analysis. Figure 7 gives the evolution by 15-day period of the frequency of each of the four classes from January to December for the West-Sahara and the Hoggar. In Figure 8, to better illustrate the east to west progression of the mid-top day and high-top day occurrence frequencies during the JJAS period, the West Sahara is divided into three sub-regions and the Hoggar into two sub regions using thresholds in longitude $\left(8^{\circ} \mathrm{W}\right.$ and $3^{\circ} \mathrm{W}$ for West-Sahara and $9^{\circ} \mathrm{E}$ for Hoggar).

(a)

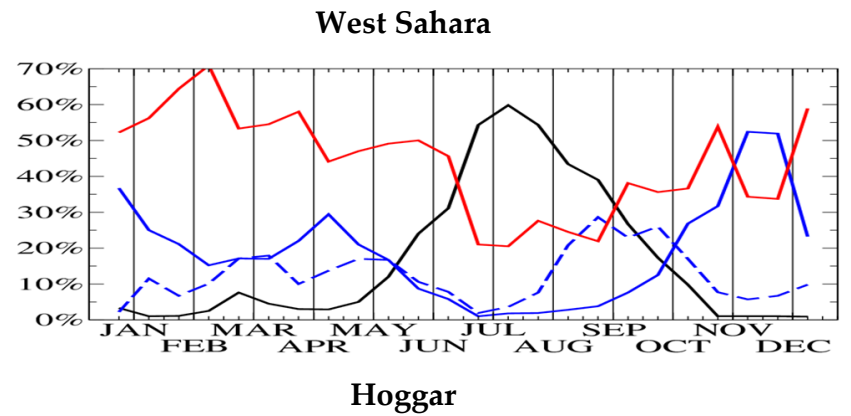

(b)

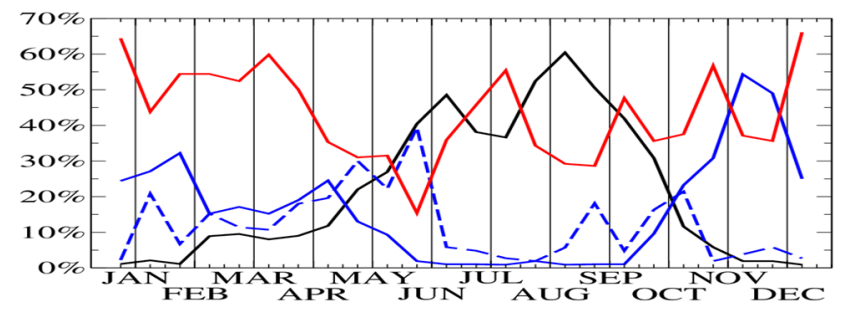

\section{Mid-top - - - High+Mid-top — High-top alone Clear}

Figure 7. (a) Frequencies of mid-top days, high-top days and clear days for West-Sahara. (b) Frequencies of mid-top days, high-top days and clear days for Hoggar. For the 2008-2014 period and 15-day periods.

In Figure 8, at the beginning of June in the eastern Hoggar, the frequency of mid-top days reaches its seasonal maximum. During the second half of June while this frequency decreases in the eastern Hoggar, it increases over the western Hoggar and over the eastern West-Sahara. In July, the maximum of mid-top day frequency is located over the central West-Sahara. During the last half of July over the western West-Sahara the mid-top day frequency increases and reaches its maximum value. In August, the frequencies decrease 
first over the central West-Sahara, then over the western West-Sahara, whilst increasing again over the Hoggar and reaching a peak in late August over the western Hoggar. The frequency of high-top days is at its highest on the Hoggar and in the eastern West-Sahara at the beginning of June. Then, after a very sharp decrease in July, it increases again in August, peaking in late August over the West-Sahara and then over the western and central West-Sahara in September (Figure 8). Throughout the season, high-top days are high-top plus mid-top days above the relief of the Hoggar (Figure $7 \mathrm{~b}$ ). In the first half of June, their frequency is as large as that of mid-top days. Over the West-Sahara, it is only in the second part of the summer that high-top days are the most frequently days with both high-top clouds and mid-top clouds (Figure 7a).

(a)
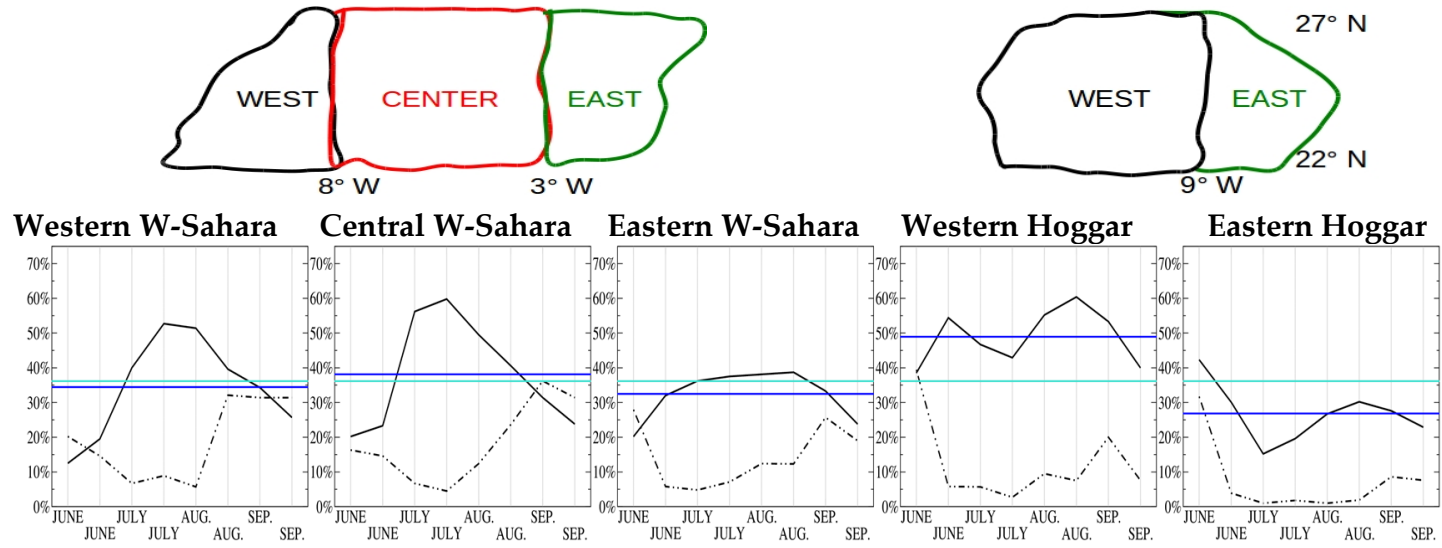

Figure 8. (a) Maps of the division of West Sahara in 3 sub-regions and of the Hoggar in 2 sub-regions. (b) Frequencies of mid-top days (solid line) and high-top days (dashed-dotted line) for each sub-region and for 15 day periods. Average frequency during JJAS (June to September) over the sub-region (blue line) and mean of the average frequency of the 2 Hoggar and 3 Western Sahara sub-regions (turquoise line).

\section{Mid-Top Cloud and Regional Atmospheric Conditions}

The goal of this section is to characterize the strength and position of the SAC and SHL, the ITD position, the importance of the SABL and the fluxes of air mass and water vapor entering the West-Sahara and Hoggar when mid-top days occur and to compare these characteristics to those observed during cloud-free days. For each of these two regions, the geopotential height at $600 \mathrm{hPa}(\mathrm{Z} 600)$, the potential temperature (T850) and the total column water vapor (TCWV) are also analysed. Moreover moisture variables (moisture and mass fluxes, ITD position, TCWV) are analyzed for high-top days. In the figures showing sample mean values, the error bars, when present, give the statistical uncertainty of the mean value, that is, the standard deviation of each sample divided by the square root of the number of days in the sample.

4.1. Intra-Seasonal Behavior of the Saharan Anticyclone (SAC), the Saharan Heat Low (SHL) and the Inter-Tropical Discontinuity (ITD) with Mid-Top Cloud

Figure $9 \mathrm{a}, \mathrm{b}$ show the evolution of the mean location of the daily barycenters of the SAC and SHL (see Section 2.3) during the JJAS period split into 15-day periods for mid-top days and clear days. Figure 10a,b provide information on daily variability in longitude around these mean values: the frequency of daily barycenter longitude (i) east of $3^{\circ} \mathrm{E}$ (ii) between $3^{\circ} \mathrm{E}$ and $3^{\circ} \mathrm{W}$ and (iii) west of $3^{\circ} \mathrm{W}$. In Figure $11 \mathrm{a}, \mathrm{b}$, the strength (mean value in the region of the maximum values) of the SAC and the strength of the SHL are given as well as the Z600 and T850 values. Figure 11c,d give, respectively, the ITD average latitude at $6 \mathrm{UTC}$ south of each of the regions $\left(12.75^{\circ} \mathrm{W}-0^{\circ} \mathrm{W}\right.$ for the West-Sahara and $0^{\circ} \mathrm{W}-12.75^{\circ} \mathrm{E}$ for the Hoggar) and the mean TCWV value at 18 UTC. 
West-Sahara

(a)

SAC

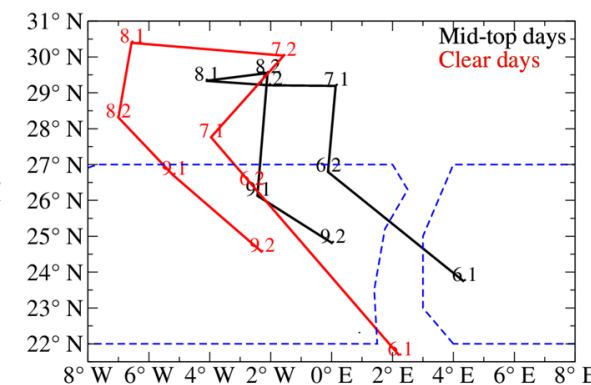

(b)

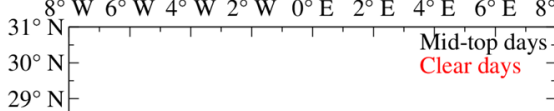

SHL

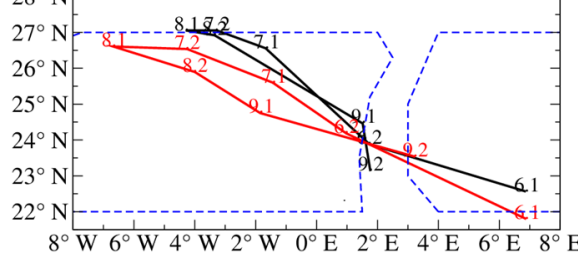

Hoggar

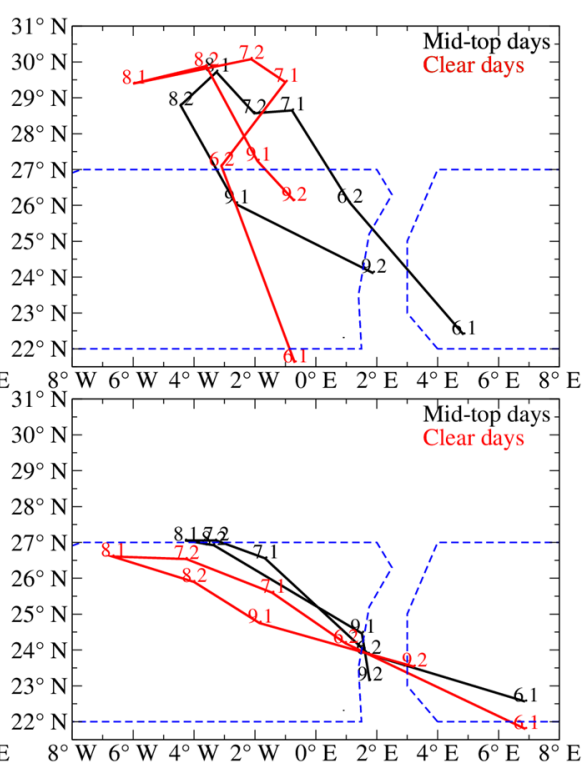

Figure 9. (a) Position of the SAC in a latitude-longitude coordinate frame for mid-top (black) and clear days (red). (b) Position of the SHL for mid-top (black) and clear days (red). Average over 15 day periods of the daily positions. Numbers indicate the month (i) which fall in the first fraction (i.1) or second fraction (i.2). Information given for West-Sahara (left column) and for Hoggar (right column). The dotted blue lines give a rough representation of Hoggar and West-Sahara boundaries.

West-Sahara

(a)

SAC

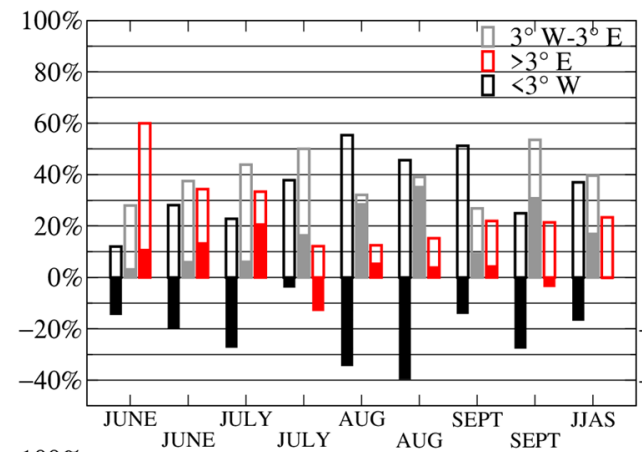

(b)

SHL

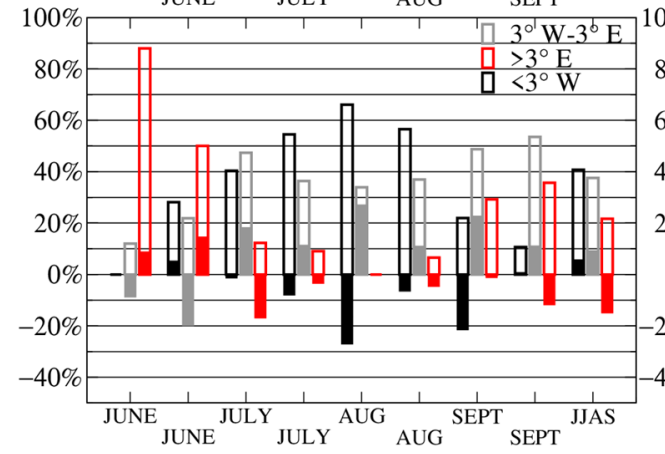

Hoggar
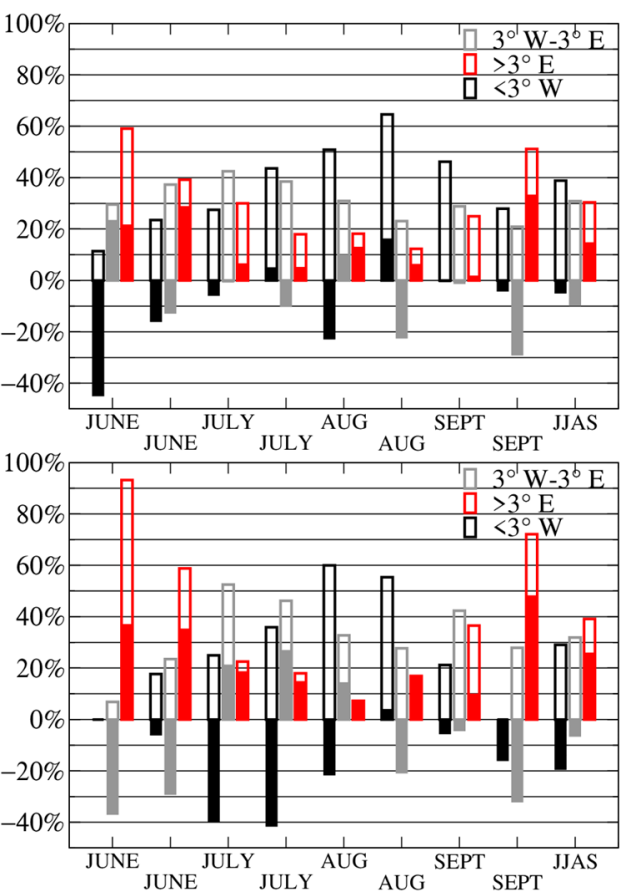

Figure 10. (a) For the SAC barycenter for mid-top days, occurrence frequency of the barycenter longitude on the west of $3^{\circ} \mathrm{W}$ (yellow contour), between $3^{\circ} \mathrm{W}$ and $3^{\circ} \mathrm{E}$ (cyan contour) and on the east of $3^{\circ} \mathrm{E}$ (brown contour). (b) For the SHL barycenter and for mid-top days, occurrence frequency of the barycenter longitude on the west of $3^{\circ} \mathrm{W}$ (yellow contour), between $3^{\circ} \mathrm{W}$ and $3^{\circ} \mathrm{E}$ (cyan contour) and on the east of $3^{\circ} \mathrm{E}$ (brown contour). The fill part of the bar gives the difference in frequency between mid-top days and clear days. Data estimated over 15 days periods. Information is given for West-Sahara (left column) and for Hoggar (right column). 

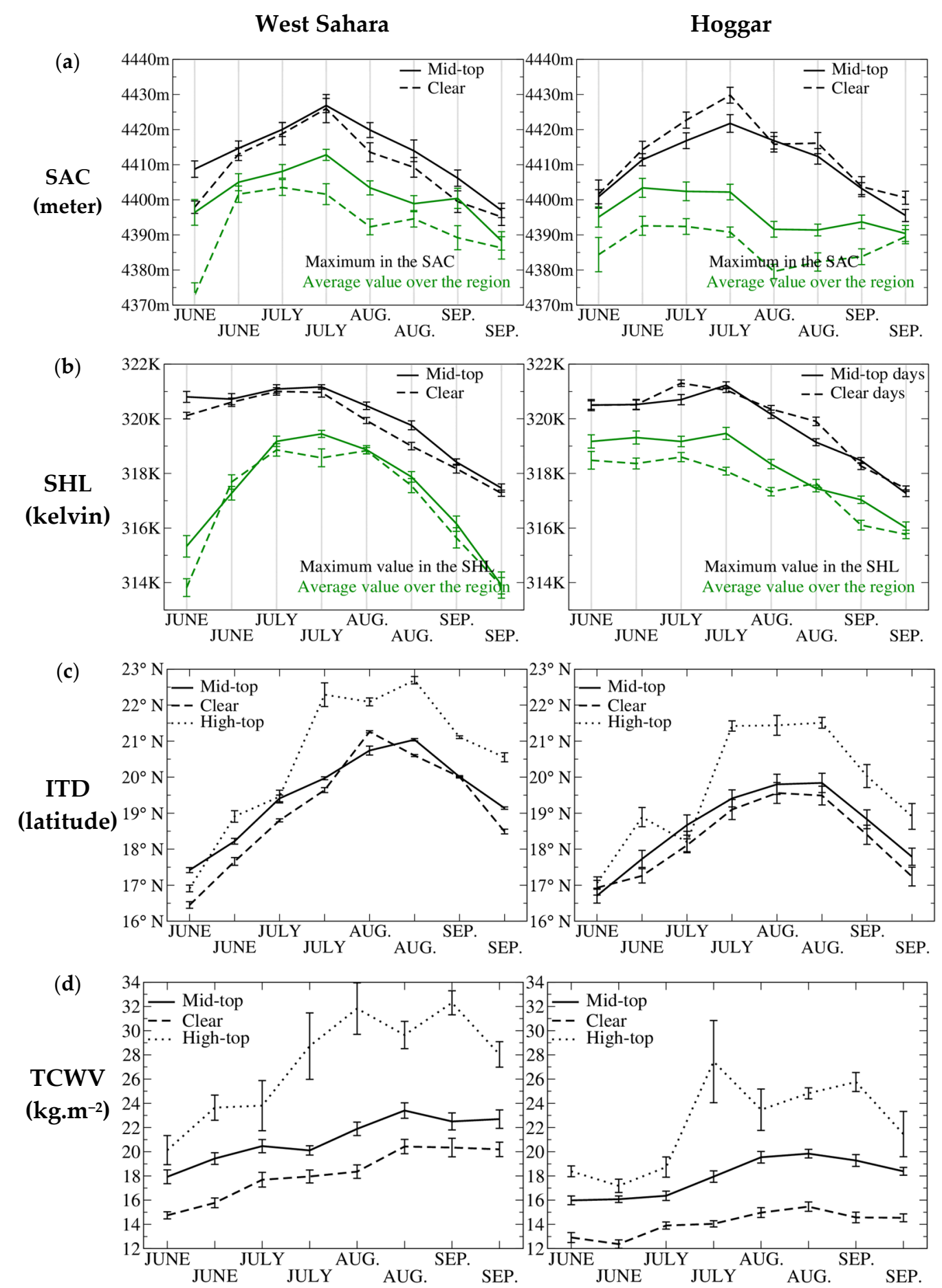

Figure 11. (a) Z600 (green) and average value of the SAC inside the region of maximum value (black) for mid-top days (solid line) and clear days (dashed line). (b) T850 (green) and average value of the SHL inside the region of maximum value (black) for mid-top days (solid line) and clear days (dashed line). (c) The ITD average latitude, for mid-top days (solid line), clear days (dashed line) and high-top days (dashed-dotted line). (d) Total column water vapor (TCWV) for mid-top days (solid line), clear days (dashed line) and high-top days (dashed-dotted line). Statistical uncertainty of the mean values (vertical bars). Data estimated over 15 day periods. Information is given for West-Sahara (left column) and Hoggar (right column). 


\subsubsection{SHL and SAC Positions and Intensity}

For both regions in Figure 9, the SHL barycenter and the SAC barycenter during mid-top days and during clear days migrate to the north-west as was observed on the monthly mean maps (Figure 3) and then retreats to the south-east at the end of August. Figure 9 shows also that the SAC barycenter moves further north and reaches the Atlas foothills, while the SHL barycenter remains south of $27^{\circ} \mathrm{N}$ at the limit of West-Sahara (Figure $9 \mathrm{~b}$ ). In both cases (mid-top days and clear days), the SAC intensity value increases until the end of July and then decreases (Figure 11a). The SHL also intensify until the end of July and then decreases.

Besides these mean behaviors, over the Hoggar, the SHL is more on the East during mid-top days than clear days and closer from the Hoggar. The SHL intensity does not show clear differences while the SHL shows higher values of the regional average T850 during mid-top days (Figure 11b). But, this increase in T850 during mid-top days is limited to eastern Hoggar (see Figure S1). For the SAC, when it is centered east of $3^{\circ} \mathrm{E}$, mid-top days are more frequent but no systematic behaviour is observed in the relative position of the SAC during mid-top days compared to clear days in Figures 9a and 10a. The SAC intensity during mid-top days is slightly weaker than during clear days, although the averaged value Z600 is stronger, indicating a regional cooling in the upper-mid troposphere characterizing mid-top days (Figure 11a).

Over West-Sahara during mid-top days, the SAC is stronger than during clear days and this difference is even more marked for the average value over the region Z600, indicating upper-mid troposphere cooling (Figure 11a). During mid-top days, the barycenter of the SAC is more to the East (Figures $9 \mathrm{a}$ and $10 \mathrm{a}$ ). For the SHL, a position between $3^{\circ} \mathrm{E}$ and $3^{\circ} \mathrm{W}$ is more frequently associated with mid-top days than clear days, except in June, when the SHL begins to migrate towards the West-Sahara. Neither the intensity of the SHL nor the T850 show clear differences between clear and mid-top days with the exception of the western West-Sahara (See Figure S1).

Dalu et al. [60] showed that the strength and position of SAC are tightly related to the SHL dynamics. The SHL drives a Walker-like subsiding to the west, which in turn reinforces the SAC. Chen [6] showed that the SAC dynamics is also influenced by the subsidence associated with the Tibetan anticyclone in the upper troposphere. A more western position of the SAC (SHL) over West-Sahara (Hoggar) during clear days than mid-top days, while the same pattern is not observed for the SHL (SAC), could reflect changes in on the relative contributions of the SHL and the Tibetan anti-cyclone on the SAC position. However, to disentangle these different contributions only on the basis of reanalysis data is not possible and beyond the scope of the paper.

\subsubsection{The Inter-Tropical Discontinuity (ITD) Position}

The mean ITD positions south of Hoggar and south of West-Sahara on their northward migration and southward retreat are slightly further north during the mid-top days than during the clear days, except in early August for the West-Sahara (Figure 11c). However, the variability around the mean values is large. High-top days coincide with a large northward shift of the ITD during the second half of the summer (Figure 11c). Whilst the maximum values of the SHL and the SAC intensity decrease from the beginning of August, the ITD continues to move northward and the TCWV values continue to increase until the end of August.

\subsection{Convergence of Mass and Humidity in the Saharan Atmospheric Boundary Layer (SABL)}

As shown in Figure 11d, TCWV exhibits significant differences between clear days (smallest value), mid-top days (intermediate value) and high-top days (largest value). These differences are driven by three sources and sinks: surface evaporation, precipitation and horizontal water convergence. In the arid conditions of the West-Sahara and the Hoggar regions, surface evaporation is a negligible source of moisture. Precipitation is also very weak except during very few isolated events (e.g., Cuesta et al. [9]) having little 
effect at the scale of half a month. Water budget depends essentially on water advection at various levels, which, in turn, depends on air mass advection. In this section the mass flow rate of water vapor entering over each domain (see Section 2.3) within five broad layers spanning the whole troposphere (surface $850 \mathrm{hPa}, 850-700 \mathrm{hPa}, 700-500 \mathrm{hPa}, 500-400 \mathrm{hPa}$, and $400-70 \mathrm{hPa}$ ) and the air mass convergence over the domains (using plots of the vertical profiles of the average vertical mass flux over the domain) are examined. These five broad layers have been chosen to capture the main characteristics of the SABL $[10,11]$. For the Hoggar, because of the high relief, daily surface pressure varies between $850 \mathrm{hPa}$ and $960 \mathrm{hPa}$, with $8 \%$ of the grid points between $875 \mathrm{hPa}$ and $850 \mathrm{hPa}$ and $34 \%$ between $900 \mathrm{hPa}$ and $850 \mathrm{hPa}$. As a consequence, $900 \mathrm{hPa}$ is the lowest pressure level of the atmosphere for which values are given. In order to avoid any interference with our study of mass flux convergence and divergence, we chose the layer Surface- $700 \mathrm{hPa}$ as lowest layer over the Hoggar. The top of this layer $(700 \mathrm{hPa})$ is well above the surface.

Figure 12 gives for mid-top days, clear days and high-top days the mean vertical profiles of horizontal mass and moisture flux convergence over the West-Sahara and the Hoggar for the JJAS period. Negative values in Figure 12 mean divergence and positive values mean convergence. At the top of the $Y$ axis, the convergence integrated over the whole vertical column (surface to $70 \mathrm{hPa}$ ), called SUM, is given.

West-Sahara

Hoggar

Mid-top Days Clear days High-top days

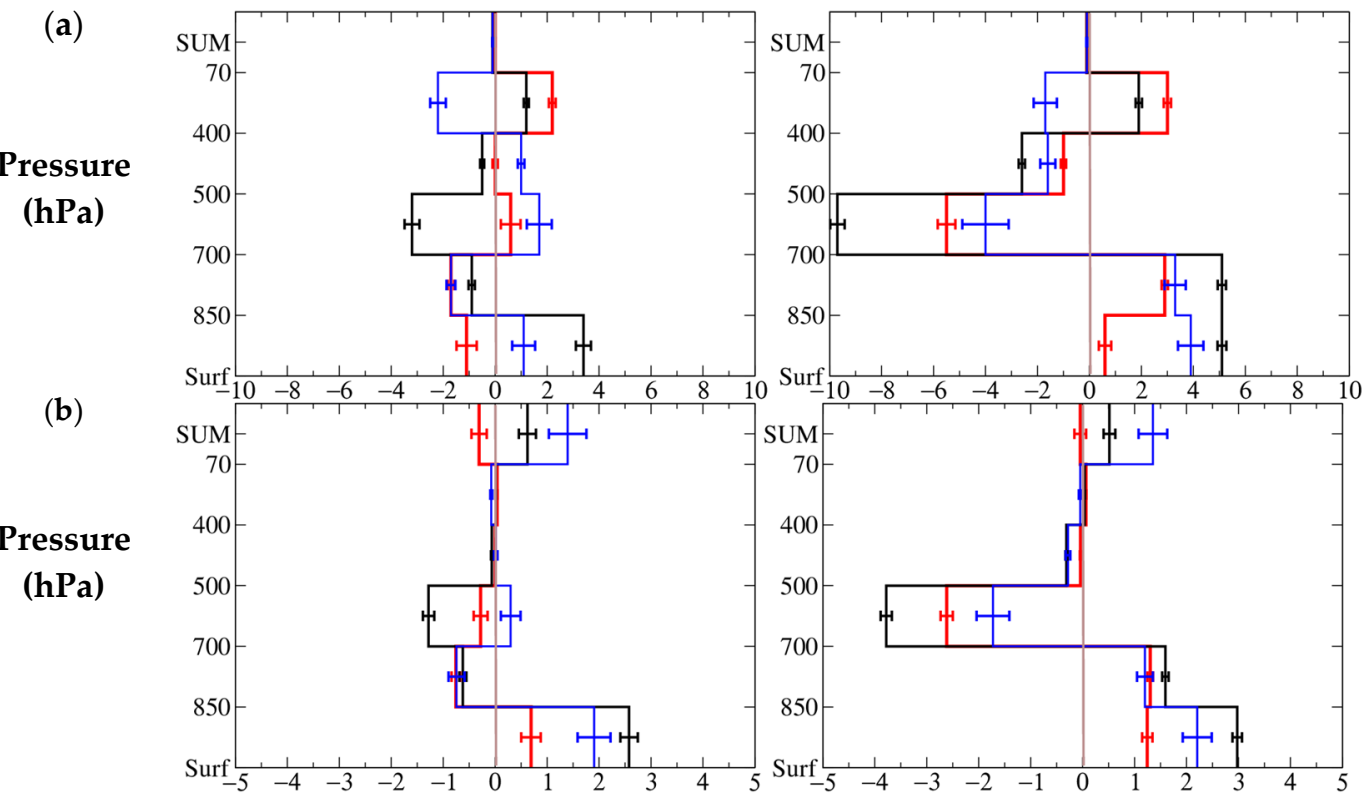

Figure 12. (a) mean vertical profile of horizontal mass flux in $\mathrm{kg} / \mathrm{m}^{2} / \mathrm{s}$. (b) mean vertical profile of horizontal water vapor flux rate value in $\mathrm{kg} / \mathrm{m}^{2} / \mathrm{d}$ and at the top of $Y$ axis the value integrated over the whole vertical column (surface to $70 \mathrm{hPa}$; SUM). Average over the JJAS period for mid-top days (black), clear days (red) and high-top days (blue). Statistical uncertainty of the mean values (horizontal bars). Information is given for West-Sahara (left column) and Hoggar (right column).

Above the Hoggar on average, moisture and mass fluxes converge between the surface and $700 \mathrm{hPa}$, and diverge between $700 \mathrm{hPa}$ and $400 \mathrm{hPa}$. In the upper troposphere, the fluxes converge on mid-top days and clear days and diverge on high-top days. The same type of circulation with convergence of flux in the low troposphere and divergence of flux in the mid-troposphere is observed over the West-Sahara on mid-top days for moisture and mass flux and on clear days for moisture flux. The positive convergence of the flux is, however, limited to the layer from the surface to $850 \mathrm{hPa}$ in the SABL. On high-top days flux converges in the mid-troposphere and diverges in the upper troposphere. 


\subsubsection{The Three Main Types of Mass and Water Convergence Profiles}

The average behaviour of the flux profiles in Figure 12, however, does not represent the different types of summer atmospheric circulation that appear in the daily profiles and in the flux profiles averaged in 15-day steps over the West-Sahara and the Hoggar (see Figures S2 and S3). To characterize these circulations the daily profiles are classified according to the sign of the flux convergence in the low troposphere, the mid-troposphere and the upper-troposphere. The three vertical layers which are considered are: (1) surface to $850 \mathrm{hPa}$ for the West-Sahara and surface to $700 \mathrm{hPa}$ for the Hoggar, (2) 700 to $500 \mathrm{hPa}$ and (3) $400-70 \mathrm{hPa}$. Three classes are sufficient to classify more than $90 \%$ of the profiles ( $85 \%$ for the humidity convergence profiles over the West-Sahara). Figure 13a displays the characteristics (the sign of convergence) of these classes (For the sake of clarity, the $400 \mathrm{hPa}$ boundary has been removed from the figure). For the first two classes labeled upper ascending profiles and subsiding profiles, convergence is positive in the upper part of the SABL (700 hPa-500 $\mathrm{hPa}$ layer in Figure 13a), while it differs in sign in the upper troposphere $(400 \mathrm{hPa}-70 \mathrm{hPa}$ layer). For the third class, labeled SABL-like profiles' convergence is negative in the upper part of the SABL and positive in the lower part of the SABL (Figure 13a). Figure 13b shows the frequency of each class for mid-top days, clear days and high-top days for the West-Sahara and the Hoggar. The frequency of profiles not classified is indicated by the gap between the top of the bar and $100 \%$; at the top of the bars is indicated the frequencies of mid-top days, clear days and high-top days among the 854 days of observations.

West-Sahara

Mid-top days Clear days High-top days (a)

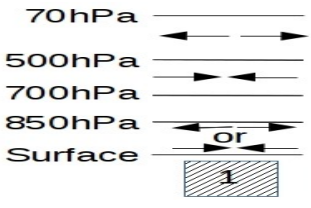

(b)
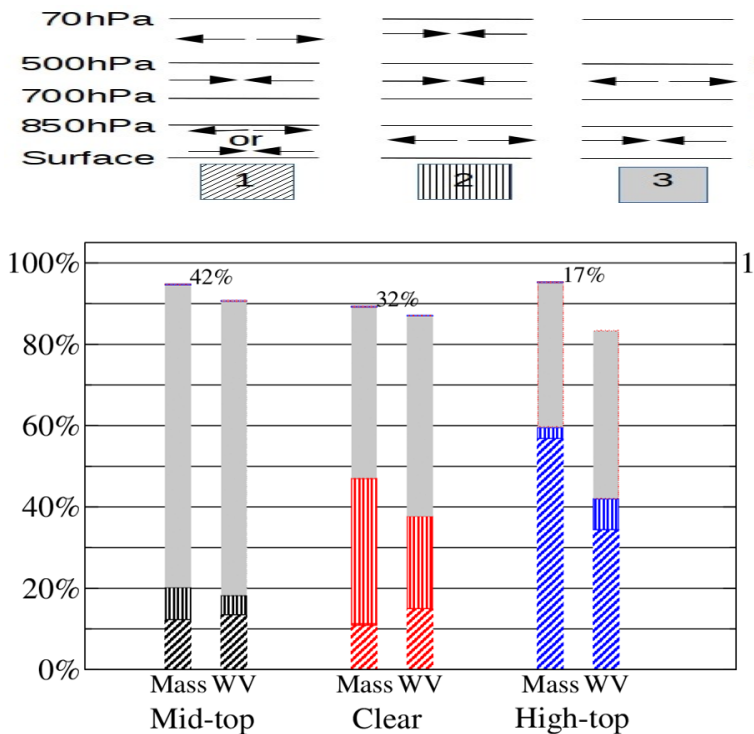
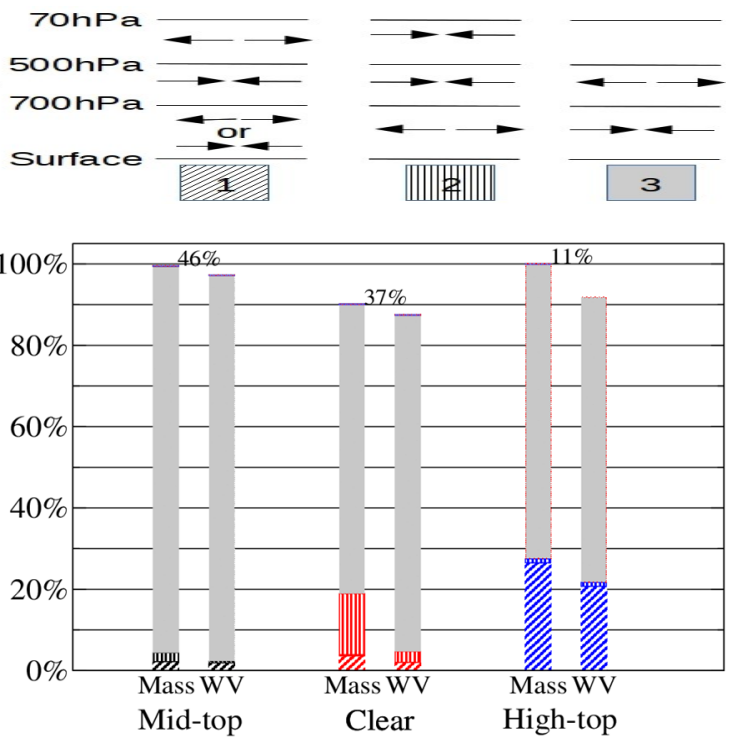

Figure 13. (a) For each of the 3 classes of convergence profile, the pressure levels and the sign of convergence value (indicated by the convergence or divergence of the two arrows) used to perform the classification. (b) for the mass (Mass) and for the water vapor (WV), occurrence frequency distribution of the convergence profiles in the 3 type classification for mid-top days, clear days and high-top days in JJAS. Information is given for West-Sahara (left column) and Hoggar (right column).

For class 1 profiles labeled "upper ascending profiles" (Figure 13a, 17\%/4\% over the West-Sahara/Hoggar) convergence is positive in the upper SABL and negative in the upper troposphere. Upper ascending profiles occur most frequently on high-top days (Figure 13b). With these profiles, the mass flow rate ascends from the upper SABL to a higher level. In the lower SABL, on high top days the flow may diverge or converge while during clear days or mid-top days the flow diverges (see Figure S5). 
For class 2 profiles labeled "subsiding profiles" (Figure 13a) convergence is positive both in the upper troposphere and in the upper SABL and negative in the low SABL. These profiles are important only on clear days (Figure 13b) and they are more frequent for the mass than the moisture $(17 \% / 7 \%$ for mass and $11 \% / 2 \%$ for moisture over the West-Sahara and the Hoggar, respectively). During subsiding profile days, the mass flow rate is subsiding at almost all levels of the troposphere and when ascending flux is observed the flow rate is small (see Figure S6).

Class 3 profiles labeled SABL-like profiles are frequent above the West-Sahara (close to $60 \%$ ) and very frequent over the Hoggar $(85 \%)$. They reach their largest frequency on mid-top days (Figure 13b). Their mean vertical profiles of vertical mass flux and their horizontal water vapor flux convergence profiles are given in Figure 14. On SABL-like profile days the mass flow ascends from the low SABL to some level within the upper SABL and subsides above (Figure 14; see also the profile of the mass flow rate distributions in Figure S4). They correspond to the paradigmatic image of Thorncroft and Blackburn [61] and of Messager et al. [10], when above the Sahara the SABL is vertically developed. In the upper troposphere, the flows converge most of the time during mid-top days and clear days. Upward flows can be observed but it is at levels well above the top of the SABL and the vertical mass flow rate is weak (see Figure S4). Exceptions are on high-top days for which, mass flow diverges frequently in the upper troposphere ( $40 \%$ of the time). Above the Hoggar, on these days, the ascending vertical mass flow from the lower SABL reaches the upper troposphere.

West-Sahara

Hoggar

Mid-top Days Clear days High-top days
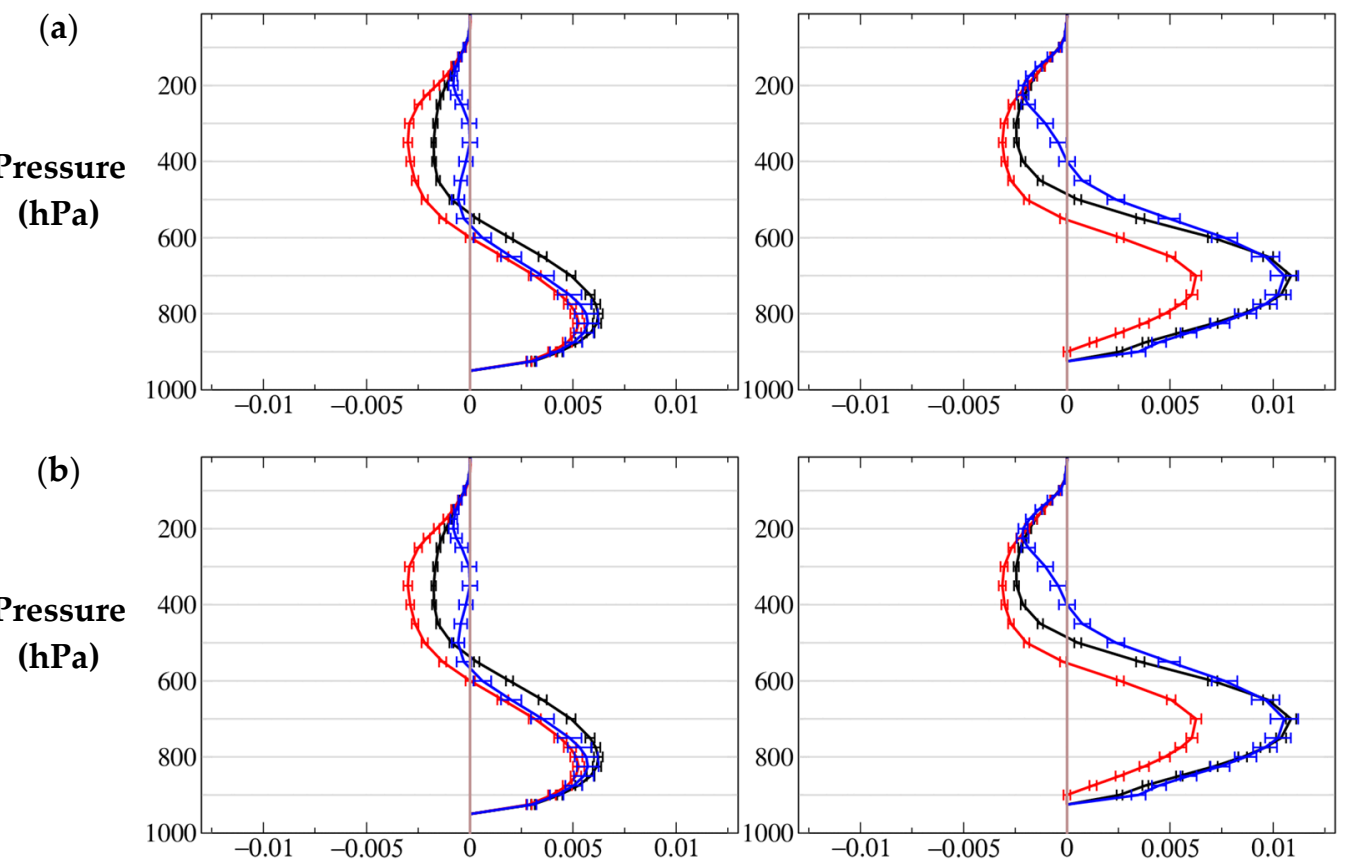

Figure 14. (a) Mean vertical profile of vertical mass flux in $\mathrm{kg} / \mathrm{m}^{2} / \mathrm{s}$ for Saharan atmospheric boundary layer (SABL)-like profiles. (b) mean vertical profile of horizontal water vapor flux rate value in $\mathrm{kg} / \mathrm{m}^{2} / \mathrm{d}$ for SAB-like profiles and at the top of $Y$ axis the integrated value over the whole vertical column (surface to $70 \mathrm{hPa}$; SUM). Average over the JJAS period. Statistical uncertainty of the mean values (horizontal bars). Information is given for mid-top days (black), clear days (red) and high-top days for West-Sahara (left column) and Hoggar (right column). In (a) the sign of the flux is positive for ascending flux and negative for subsiding flux. In (b) the sign of the flux rate is positive for convergence and negative for divergence. 
During the season while the frequency of clear, mid-top, and high-top days vary (Figure 7), the frequencies of these three classes of profile vary. Figure 15 shows the frequency of each profile class for mid-top days, clear days and high-top days for 15-day periods and for the West-Sahara and the Hoggar. At the top of the bars, the frequencies of mid-top days, clear days and high-top days that are close to the number of days used to calculate frequency values, is indicated. Despite the large uncertainties induced by the small size of some samples, the behavior of the intra-seasonal evolution of these frequencies allows some conclusions to be drawn. It should be noted that the total number of days in a period is equal to a maximum of 105 or 112 ( 7 times 15 or 16 days). For some periods, this number may be slightly lower due to a few days missing in the SEVIRI data.

West Sahara

Mid-top Days Clear Days

High-top Days

(a)
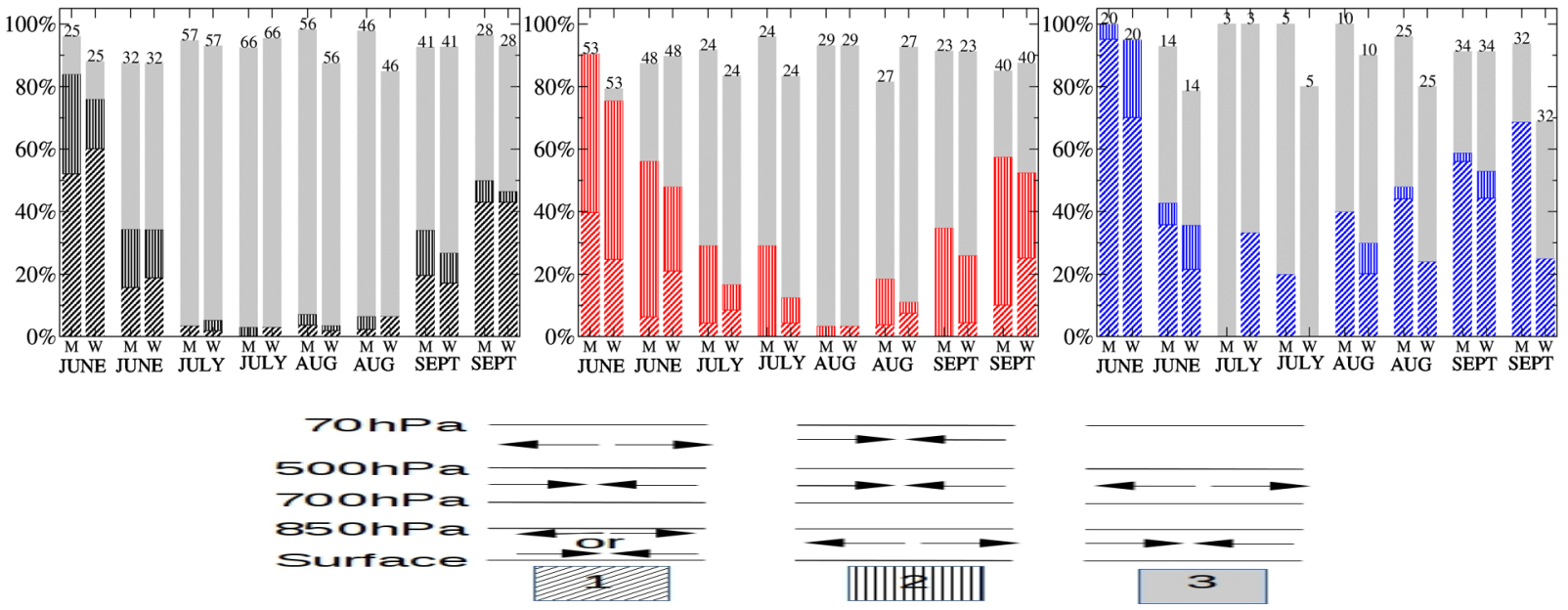

Hoggar

(b)
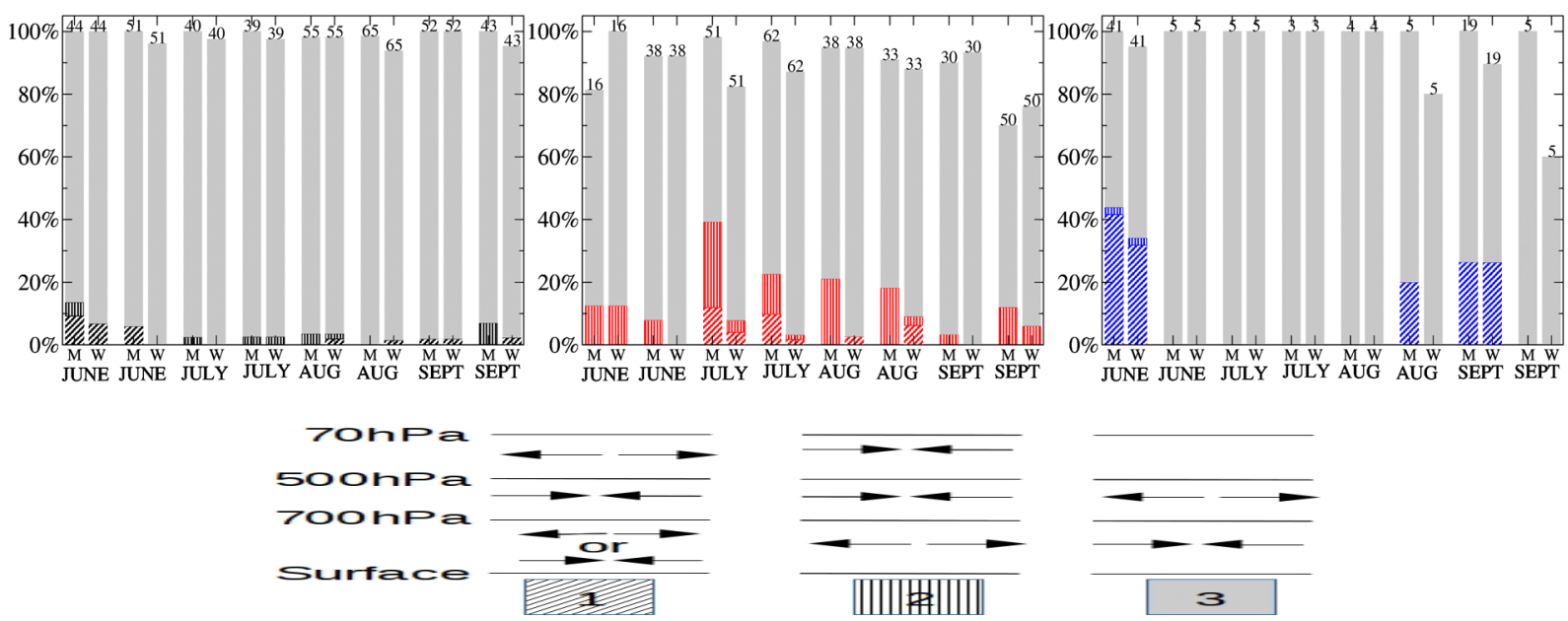

Figure 15. (a) For mid-top days (left), clear days (center) and high-top days (right), for the mass $M$ and for the water vapor $\mathrm{W}$, occurrence frequency distribution of the convergence profiles in the 3 type classification estimated over 15-day periods over West-Sahara; the frequency of profiles not classified indicated by the gap between the top of the bar and $100 \%$; at the top of the bars, the number of mid-top day, clear day and high-top day. (b) same as (a) but for the Hoggar. 


\subsubsection{Intraseasonal Variations of Convergence Classes over West-Sahara and Hoggar}

\section{- West-Sahara}

In July-August the circulation associated with SABL-like profiles is the most frequent ( $82 \%$ and $86 \%$ in the second half of July). The mean convergence of humidity in the low SABL is maximum (Figure S3). Mid-top days are at their maximum of occurrence and coincide exclusively with these conditions of circulation (Figure 15a). For clear sky days, the frequency of SABL-like profiles is close to $100 \%$ in the first part of August (Figure 15a).

In the first half of June, SABL-like profiles are rare, and upper ascending profiles and subsiding profiles reach their maximum of occurrence (Figure 15a). In the lower SABL mass and humidity diverge. Air and moisture enter the region almost exclusively through the middle levels (Figure S3). During the second half of June both the mid-top day frequency and the SABL-like profile frequency increase; these increases are highest on the eastern part of West Sahara (see Figure 8 and Figure S7).

In September, the frequency of subsiding and upper ascending profiles re-increases (Figure 15a). However, occurrence frequency of SABL-like profiles remains non-negligible and the frequency of mid-top days is still 40\%. In the lower SABL convergence of mass and moisture is still very frequent (70\%). Positive mass convergence in both lower and upper SABL characterizes half of the days with high-top clouds and upper ascending mass profiles, which is not the case in June. On most high-top days, in addition to high clouds, there are also mid-level clouds (Figure 7a red curve), which is also not the case in June.

\section{- Hoggar}

Over the massif of the Hoggar, SABL-like profiles are very frequent throughout the season (Figure 15b). For mid-top days, the occurrence of upper ascending profiles or subsiding profiles is rare. In the first half of June, on average, the ascending mass motion in the SABL reaches $400 \mathrm{hPa}$ (Figure S3). For clear days, as opposed to the West-Sahara, the frequency of subsiding mass profiles is maximum in July and August (Figure 15b). This maximum is larger on the East part of the Hoggar region where the frequency of subsiding mass profiles exceeds $40 \%$ during July and August (Figure S7).

There are two periods, the first half of June and the first half of September, where upper ascending profiles for both mass and moisture occur (Figure 15) and where the frequency of high-top day is significant. In the first half of June, when the occurrence of high-top days is as high as those of mid-top days (40\%, the frequency of upper ascending profiles for high-top days reaches $40 \%$ for mass convergence and $32 \%$ for moisture convergence (Figure 15b). In the first half of September, when the high-top day frequency reaches a second but weaker peak, upper ascending profiles are again observed but less frequently.

\section{Discussion}

Cloud cover above the Sahara is dominated by high-top clouds from November to April, while mid-top clouds prevail from June to September (Figure 6). In winter, the Sahara and North Africa are under a regime of high surface pressure, and the mean air temperature near the surface is below $16^{\circ} \mathrm{C}$ [22]. The lower troposphere circulation is dominated by the northeasterly Harmattan wind regime, characterized by maximum strength and southward extension during this season. The air is very dry, and water vapor (TCWV) does not exceed $15 \mathrm{~kg} / \mathrm{m}^{2}$ [22]. These conditions do not favor the development of a deep boundary layer and the formation of clouds at its top. In the upper troposphere, extratropical lows associated with the westerly winds and the STWJ, which then on average cross North Africa from west to east, between $18^{\circ} \mathrm{N}$ and $28^{\circ} \mathrm{N}$, can penetrate far south, favoring the transport of humid tropical air northeastward over the North African continent. These northward inflows of tropical moisture are very often accompanied by bands of high altitude cloud called tropical plumes [62-65]. In spring, the occurrence of tropical plumes continues to characterize the upper tropospheric circulation $[22,43,65]$. In the lower troposphere, moist and fresh air is advected inland by northwesterly winds from the Atlantic and the southwesterly monsoonal flow from the coast of Guinea. Simultaneously, temperatures 
increase in the Sahara from February onwards $[9,66]$ leading the convective boundary layer to rise to almost $3 \mathrm{~km}$ since March over the Hoggar [9]. The occurrence of mid-top days increases over the Hoggar and remains around 10\% until the end of April. In May after the strong northward migration of the ITD during April [22,67], as the West African Thermal Low (WAHL) migrated from $14^{\circ} \mathrm{N}$ to $20^{\circ} \mathrm{N}$ [68], the occurrence of mid-top days increases sharply. A schematic of the circulation during spring is given in Figure 16a.

(a)

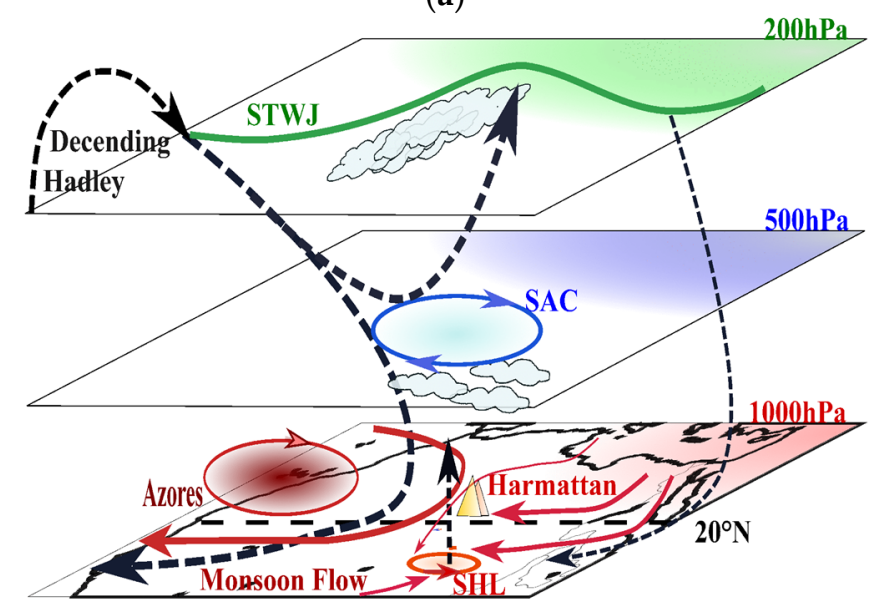

(b)

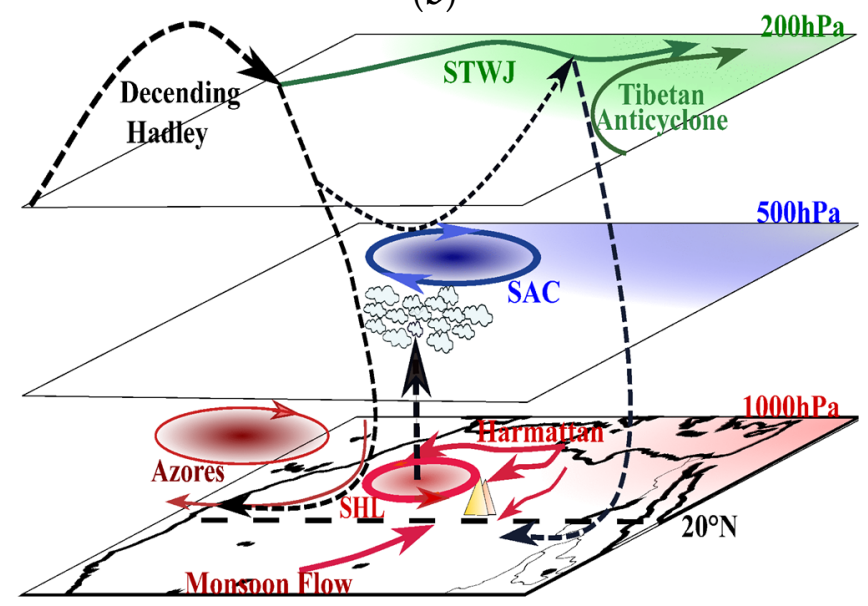

Figure 16. Circulation over West Africa during (a) Spring and (b) Summer, when the SHL (thick red circle) settles over the northern edge of West-Sahara. At low levels, the SHL and Azores anticyclone (thick and thin red circles with arrows, respectively), the Harmattan wind (north-south oriented red arrow), the Atlantic inflow (red arrow around the Azores anticyclone) and the monsoon flow (south-north oriented red arrow). In the mid-troposphere is the Saharan anticyclone (blue circle with arrows). In the upper troposphere are the sub-tropical westerly jet (STWJ in green) and the Tibetan anticyclone (green arrow). The vertical circulation between the three levels is highlighted as dashed black arrows (descending branch of the Hadley cell, descent of a Rossby wave over the Mediterranean, ascendance in the SHL). For the SHL and the SAC and Azores anticyclone, strengthening of the intensity is indicated by an increase in brightness color. Increasing thickness of arrows indicate an increase in the strength of the circulation. The Hoggar position is indicated by the two triangles. The location of mid-level clouds is also indicated.

From June onwards, simultaneously with the progressive installation from east to west of a deep SABL that persists until September and the associated circulation pattern (Figure 15 and Figure S7), the frequency of mid-top days increases gradually also from east to west to remain high until September (Figures 7 and 8). During this period, three phases are observed in the SHL and SAC positions: (i) the SHL and the SAC move northwest in June, (ii) remain in their northernmost position in July and August, and (iii) retreat southeast in September.

The first half of June is in the continuity of May, with the SHL located at the foothills of the Hoggar $[4,9,23,69]$ and most frequently east of $3^{\circ} \mathrm{E}(80 \%$; Figure $10 \mathrm{~b})$. This position of the SHL is characteristic of the period preceding the monsoon onset. The cold ventilation from the Atlantic Inflow continues to penetrate far inland [24,25] over the West-Sahara before curving in the south-west direction (Figure 4). With this cold ventilation in the low layer, the boundary layer during daytime remains shallow [25] and the frequency of mid-top days remains small especially on the western edge of West-Sahara (Figure 8; Todd et al. [25]). Large-scale subsidence and clear sky are very frequent. Moisture and mass converge in the upper SABL and diverge in the low SABL. Meanwhile, the south-westerly monsoon flow and the north-easterly Harmattan flowing between the Aïr and the Hoggar converge towards the SHL [1,9]. Thanks to the SHL cyclonic circulation, moisture from the monsoon flow can be advected over the Hoggar. During the Fennec experiment in June 2011, at Bordj Baji Mokhtar (BBM), the Fennec supersite-1 (Figure 1) located on the southwestern boundary of the $\operatorname{Hoggar}\left(21.38^{\circ} \mathrm{N}, 0.92^{\circ} \mathrm{E}\right)$, Marsham et al. [17] in the first 
half of June during the monsoon pre-onset period observed some cases of monsoon surge with moisture and cold pools embedded in the monsoon flow. Over the West Hoggar and on the eastern edge of the West-Sahara, the frequency of mid-top day increases. Over the East Hoggar, the frequency of mid-top days reaches its seasonal maximum (Figure 8) and as well as the frequency of SABL-like profile days (Figure S7). In the upper troposphere, the westerly circulation is still present but the anticyclonic circulation in the mid-troposphere is now centered over the South-West Hoggar (Figure 9a). This could favor the transport of humidity from the south-west over Hoggar by the mid-level which in turn could favor the occurrence of ascending profiles (Figure 15b) and high clouds accompanied by midlevel clouds over Hoggar (Figures $7 \mathrm{~b}$ and 8) [53,62,70]. Marsham et al. [17] in June 2011 observed this type of circulation at BBM before the monsoon onset with a moist layer and southwesterly winds at the top of the SABL overriding dry air associated with northerly winds during a period where an upper level trough was located northwest of BBM. In the second part of June, on average, the northwestward moving SHL is still close to the Hoggar (Figure 10b) but most frequently to the west of the Hoggar (Figure S8). This shift to the north-west is one indicator of the monsoon onset $[4,23,49]$. The Harmattan wind intensifies, splitting around the Hoggar into two axes. The convergence of the monsoon flux and of the Harmattan flux is now frequently on the West of Hoggar. At BBM during June 2011, the monsoon influence becomes prevalent. Mid-top day frequency reaches a first maximum over the Western Hoggar and increases over the Eastern West-Sahara (Figure 8). However, in the eastern Hoggar, the frequency of subsiding profiles and clear sky increases whilst those of mid top days decreases abruptly. The high orography acting as an obstacle to the Harmattan flow may have a role in this abrupt decrease. In this respect, Birch et al. [71] emphasize the intensification of the Harmattan flow deviated on the North of the massif and, in its descent to the south, the cooling effect of this flow on the top of the boundary layer on the eastern side of the Hoggar. In the upper troposphere, the frequency of high-top days decreases sharply over the Hoggar and eastern West-Sahara (Figure 8) while the subtropical anticyclonic belt strengthens, westerly winds shift northward, and in the mid-troposphere the SAC moves northwestward (Figure 9a). This makes it more difficult for mid-level moisture to be transported from the tropics to the Hoggar and thus makes it more difficult for high-altitude cloud to form over this region.

In July, after the monsoon onset, deep convection is now forming more frequently over the Northern Western Sahel which may reduce the possibility of moisture inflow by cold pools over the Hoggar. These changes should contribute to the decrease in the average cloud frequency in July over this region. However, the mid-top day frequency remain above $40 \%$ above West-Hoggar. The large surface heating during the day over this region caused by the elevated and dark surface inducing flux convergence [71] could be one reason for that. During the Fennec experiment, Engelstaedter et al. [72] observed two pathways for the monsoon flow. One curves around the SHL cyclonic circulation located west of the Hoggar and is particularly present in the morning, the other is observed during the afternoon, heading towards the Hoggar [71].

Over West-Sahara in July and the first half of August, the frequency of cloud formation at the top of the SABL gradually increases westward (Figure 8) thanks to the development of a deep SABL (Figure 15 and Figure S7) which itself is linked to the northwestward movement of the SHL and the SAC and the maintenance of their strength. Another crucial parameter for the formation of these mid-top clouds is a moisture supply in the SABL. A more frequent SHL on the west (Figure 10 and Figure S8) coincides with a decrease of the cold Atlantic inflow over North West Africa (see e.g., Todd et al. [25] and Grams et al. [24]), and an intensification of the Harmattan flow between the Hoggar and the Atlas Mountains [1,73]. This flow which warms up above the heated surface is captured by the SHL cyclonic circulation on its northwest flank [73], while the monsoon flow converges with the cyclonic circulation on its southeast flank [4]. This circulation pattern leads to a strong increase of mass convergence but also of moisture convergence in the lower SABL above the West-Sahara (Figure S3). Another cause of the increase in the moisture flux 
over the West-Sahara could be the larger frequency of cold pool initiated by more frequent deep convection in the Northwestern Sahel after the monsoon onset, as well as cold pools generated by convection over Atlas [74]. At the end of July, the SHL is at its maximum strength and the frequency of mid-top days over central and West-Sahara too. The SHL continues to progress westward in the first part of August and the SABL-like circulation reaches its maximal extension toward the West. Mid-top clouds occur now close to the coast. In July, the frequency of high-top days reaches a minimum on both the Hoggar (see also Cuesta et al. [9]) and West-Sahara, while in the upper troposphere the westerly flow reaches its northernmost position and the subtropical anticyclonic belt its maximum strength. A schematic of this circulation is given in Figure 16b.

During the second half of August and in September, the SAC and the SHL, the Tibetan anticyclone and westerly winds in the upper troposphere have resumed their June position. The northerly flow from Harmattan to the east of the Hoggar decreases as does the subsidence in the upper and middle troposphere. But, the frequency of SABL-like profiles remain high during the second part of August (Figure S7) and south of the Sahara, the ITD is still very close to its northernmost position during the second part of August [22]. Humidity continues to increase over the West-Sahara and the Hoggar (Figure 11), and mid-top day frequency reaches its highest value of the season over the Hoggar $(60 \%$ at the end of August). In the West, mid-latitude lows penetrate southwards, favoring humidity provided by the south-west branch of the SAC in the mid-troposphere over the Sahelian coast to be transported northeastwards [62]. In response to this circulation, the occurrence frequency of ascending profiles and high cloud increases first over western and central West-Sahara and then in the first half of September over the eastern edge of West-Sahara and Western Hoggar (Figure 8 and Figure S7). On most high-top days, in addition to high clouds there are also mid-top clouds which is not the case in June when the SABL is not developed.

As described in (Garcia-Carreras) [11] the diurnal cycle of the Saharan convective boundary layer $(\mathrm{CBL})$ is characterized by a slow growth during the morning and the first part of the afternoon. The fully developed CBL exists, therefore, only for a few hours after 1600 UTC, until sunset ( 1800 UTC). After sunset, the fully developed CBL becomes a residual layer which top marks the top of the SABL. Our hypothesis is that the midtop clouds are mainly boundary layer clouds, i.e., clouds formed at the top of some of the thermals within the Saharan CBL, favored by the gradual moistening of the residual layer by the CBL [11]. Their occurrence should be maximum, therefore, at the end of the afternoon, after the CBL has reached its maximum vertical extension. This ties in with Figure $5 b, c$ where the occurrence of mid-top clouds is maximum between 1900 UTC and 2100 UTC. However, the maintenance of the mid-top cloud occurrence during the night and even its slight nocturnal growth in September over the West Sahara requires another mechanism. We hypothesize that this mechanism is the radiative cooling of clouds. But we expect such a process to yield the same weak decrease of mid-top clouds over the Hoggar as over the West-Sahara, in apparent contradiction with the fast decrease observed over the Hoggar. Mid-top cloud occurrences over the Hoggar and the West Sahara, however, reach very similar minimum values, maximum occurrences are very different. In surface observations of the cloud cover (see Section 3.2.1) cumulus clouds are more frequent than alto-cumulus over the Hoggar while over the West-Sahara it is the opposite. This might be due to the enhancement of the Hoggar CBL by orographic processes (especially the heating of mountain slopes by incoming short wave radiation). The observations are, therefore, compatible with mid-top clouds being driven by two processes: (i) mid-top clouds are generated by CBL processes at the end of the afternoon, this mechanism generating more clouds over the Hoggar than over the West Sahara thanks to insolation induced orographic processes; (ii) mid-top clouds are maintained at a similar level over the Hoggar and over the West Sahara by radiative cooling. 


\section{Summary and Conclusions}

A climatology of cloud occurrence frequency and of cloud top distribution among the low, middle and high levels of the atmosphere has been constructed for the Sahara. To the best of the authors' knowledge, this is the first quantification of the cloud occurrence over Sahara by type in summer and of its spatial distribution, at diurnal, daily and intra-seasonal scale, done here for the 2008-2014 period. For this, the SAFNWC cloud product derived from radiance data of the SEVIRI radiometer on board the MSG geostationary satellite and available at a scale of $3 \mathrm{~km} \times 3 \mathrm{~km}$ every $15 \mathrm{~min}$ is used to build a 7-year climatology (from 2008 to 2014).

Based on this climatology, it is confirmed that over the entire diurnal cycle, the cloud cover topped at mid-level is the major characteristic of the cloud cover over the Sahara in summer. It is shown that its frequency of occurrence is minimal around 10 UTC and maximum at the end of the day. It is shown that the altitude of its top, $400-450 \mathrm{hPa}$, which is slightly above the altitude of the top of the Saharan residual layer, is stable during the season. This contrasts with the rest of the year when high-top cloud is most frequent.

Another key feature of the mid-top cloud over the Sahara in summer is revealed: this cloud cover gradually extends during the season from the eastern Hoggar to central and then western West-Sahara. This extension is not accompanied by a uniform increase in the occurrence frequency of mid-top clouds. When days are classified according to their type of cloud cover, the frequency in JJAS of mid-top days is highest in the western Hoggar with an average value of $49 \%$. In the central part of the West-Sahara, this average value reaches $38 \%$, while it is only $32 \%$ over the eastern West-Sahara at the edge of the Hoggar. The lowest average frequency, $27 \%$, is observed over eastern Hoggar.

When the whole season is partitioned into eight 15-day periods it is found that: (1) the changes in frequency of mid-top days is indicative of surface heating, low-level circulation and low level convergence of humidity (2) whilst a main factor governing high-top day frequency during the summer is the mid-latitude air intrusions in the upper levels and their interaction with the mid-troposphere anti-cyclonic circulation.

The intra-seasonal variations in mid-top days are coincidental with the move of the SHL, the SAC and the ITD diagnosed with the ERA-interim reanalysis. Associated with the north-west move of the SHL and the SAC, the depth of SABL gradually increases from east to west. At the same time, the frequency maximum of mid-top days, which is situated over the east of the West Hoggar at the beginning of June, moves westward to reach the west of the West-Sahara at the end of July. With the retreat of the SHL and the SAC to the southeast, this frequency maximum of mid-top days shifts back to the east of West Hoggar in late August.

There are also some features of the large-scale atmospheric parameters specific to mid-top days when compared with clear days, irrespective of the period. Over the Hoggar and the West-Sahara, during mid-top days, the geopotential height at $600 \mathrm{hPa}$, a proxies for the strength of SAC over the region, increase in comparison to clear days. The water vapor convergence also increases and a weak but northward move of the ITD is observed. Mid-top clouds and clear sky are most frequently associated with large scale subsidence in the upper troposphere. While for clear days subsidence in the SABL is more frequent, for mid-top days there is a convergence of mass and humidity in the low part of the SABL and divergence in the upper part of the SABL. The diurnal cycle of these mid-top clouds and the altitude of their summit are in agreement with clouds that form at the top of the thermals within the Saharan boundary layer. The radiative cooling that they then produce and which induces an increase in the geopotential height, allows their maintenance.

The transition from a high-top cloud cover to a mid-top cloud cover in June coincides with the northward move of the upper and middle level westerly flow and the extension to the western Tibetan anti-cyclone whilst its moves northward. With their retreat towards the south in August, the frequency of high cloud cover recovers and upper level troughs from mid-latitude can again penetrate further south. In early June, high-top day frequency is maximal over the Hoggar and the east of the West-Sahara. At the end of August and in 
September high cloud frequency is maximal over the west and center of the West-Sahara. Our hypothesis is that this high cloud cover is produced by the moisture transported from the south by the south-west branch of the SAC and captured by an upper level trough as described in Knippertz [62] and Knippertz et al. [53].

It has been have shown that the occurrence of clouds above the West-Sahara and Hoggar coincides with a convergence of enhanced moisture compared to a clear sky occurrence. The next step will be to characterize the moisture flux source leading to the convergence of moisture on the Hoggar and the West-Sahara. The northward move of the ITD during the mid-top days and high-top days indicates that at least some of the moisture that converges on the Hoggar and the West-Sahara originates from the monsoon region. Several case studies have shown the importance of cold pools initiated by the convective systems in the ITCZ and also, but less frequently, by cold pools initiated by convection over the Atlas to bring moisture over Western Sahara and the Hoggar. But several case studies have also shown the importance of the humidity brought to the West-Sahara by the Atlantic-West flux [25] or from the Mediterranean by the Harmattan [73,75]. The role of AEW which carries moisture from the monsoon region towards the Sahara for mid-top and high-top cloud formation should also be investigated. Such a study could help interpret the changes in location of the SAC and the SHL when mid-top clouds occur relative to clear sky situations. Future research will also focus on the role of dust loading in controlling the formation of mid-top clouds.

Supplementary Materials: The following are available online at https://www.mdpi.com/article/10 .3390 /atmos12040428/s1, Figure S1: Average Z600 and T850 values per 15 day period for the 3 sub regions of West-Sahara and the 2 sub-regions of Hoggar for mid-top days and clear days, Figure S2: Distribution of vertical mass flux as a function of pressure level during JJAS, Figure S3: Mean vertical profile of vertical mass flux and mean vertical profile of horizontal water vapor flux convergence per 15 day time period, Figure S4: Distribution of vertical mass flux as a function of pressure level for the SABL profiles and for mid-top days, clear days and high-top days, Figure S5: Distribution of vertical mass flux as a function of pressure level for the upper ascending profiles and for mid-top days, clear days and high-top days, Figure S6: Distribution of vertical mass flux as a function of pressure level for the subsiding profiles and for mid-top days, clear days and high-top days, Figure S7: Frequencies per 15 day period of SABL profiles, upper ascending profiles and subsiding profiles for each of the 5 sub-regions title, Figure S8: Variation in the longitude position of the SHL during the 15-day periods, Table S1: Domains and thresholds for determining the position and strength of the SHL, of the SAC, of the Tibetan anticyclone and of the Azores anticyclone, Table S2: Evolution of the monthly average frequency of high-top and mid-top clouds during the year.

Author Contributions: Conceptualization, N.S., G.S., M.G., J.-Y.G., C.F. and J.C.; Formal analysis, N.S., G.S. and J.-Y.G.; Funding acquisition, N.B. and C.F.; Methodology, N.S. and G.S.; Supervision, G.S.; Writing-original draft, N.S. and G.S.; Writing—review and editing, M.G., J.-Y.G., C.F., J.C. and N.B. All authors have read and agreed to the published version of the manuscript.

Funding: Funding was provided for this research by the «Programme National Exceptionnel (PNE) du MESRS “Ministères de l'Enseignement Supérieur et de la Recherche Scientifique d'Algérie"» and by the national programme «Les enveloppes fluides et l'environnement (LEFE) of CNRS INSU» under grant AO2014-862487 and the support of the Centre National d'Etudes Spatiales (CNES) in the frame of the «Expecting Earth-Care, Learning from A-train» project.

Data Availability Statement: The SEVIRI/MSG CTTH data used in this study are openly available at the AERIS/ICARE French data center (http:/ / www.icare.univ-lille1.fr/archive?dir=GEO/ MSG+0000/SAF_NWC/ (accessed on 23 March 2021)); CALIOP L2 and L3 data are publicly available at NASA/LaRC/SD/ASDC https:/ / asdc.larc.nasa.gov/project/CALIPSO?level=3 https: / / doi. org/10.5067/CALIOP/CALIPSO/CAL_LID_L2_05kmMLay-Standard-V4-21 (accessed on 23 March 2021) and https:/ / doi.org/10.5067/CALIOP/CALIPSO/LID_L3_GEWEX_Cloud-Standard-V1-00 (accessed on 23 March 2021). 
Acknowledgments: Nada Selami would like to thank Frédéric Hourdin, Martine Maherou and all the members of the LMD laboratory for their welcome and hospitality during her stays at the LMD on the Sorbonne-Université site.

Conflicts of Interest: The authors declare no conflict of interest.

\section{Appendix A. Pressure Thresholds for the Separation between Low-Top Clouds, Mid-Top Clouds and High-Tpop Clouds}

The SEVIRI cloud top pressure distributions over the West-Sahara and Hoggar for the JJAS period (Figure A1) show a sharp peak in the mid-troposphere at $400 \mathrm{hPa}$ with abrupt decreases between $400 \mathrm{hPa}$ and $350 \mathrm{hPa}$ and between 400 and $500 \mathrm{hPa}$. Another but weaker peak occurs at $275 \mathrm{hPa}$. Assuming that these peaks in the cloud top pressure distributions are related to high-top cloud and mid-top cloud occurrence, two thresholds are chosen: one at $350 \mathrm{hPa}$ to separate mid-top clouds from high-top clouds and the other at $500 \mathrm{hPa}$ to separate mid-top clouds from clouds with lower tops. These two thresholds are outside the range of values commonly used in the community. For example in the intercomparison of cloud climatology in the frame of the GEWEX (The Global Energy and Water Exchanges) project and the related ISCCP (International Satellite Cloud Climatology Project) project [76,77], the separation between high-top cloud and mid-top cloud is $440 \mathrm{hPa}$ and the separation between mid-top cloud and low-top cloud is $680 \mathrm{hPa}$. As shown by the cloud top pressure distributions over West-Sahara and Hoggar observed by SEVIRI and also by the CALIOP lidar (Figure A1b and Appendix C), these thresholds are not adapted to the specific characteristics of the cloud cover over regions such as the Sahara where the boundary layer is very deep.

(a)

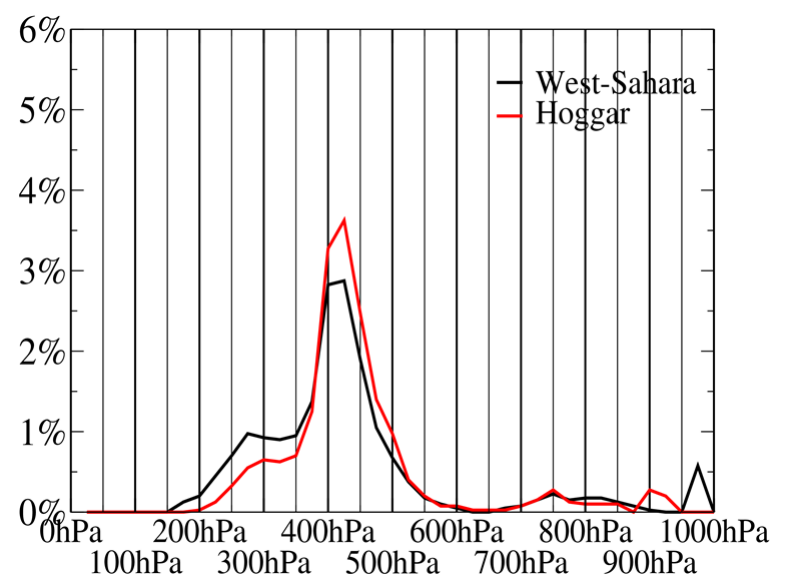

(b)

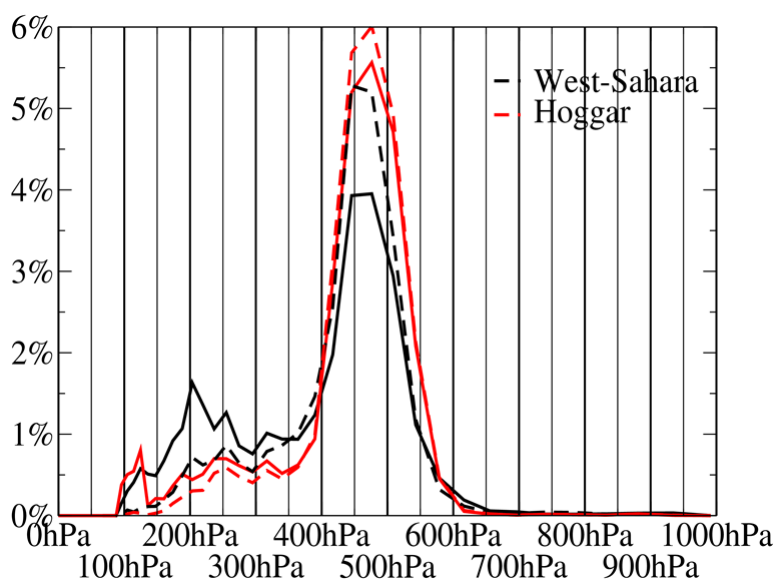

Figure A1. (a) Occurrence frequency distributions of Spinning Enhanced Visible and Infrared Imager (SEVIRI) cloud top pressure for West-Sahara (black line) and Hoggar (red line). (b) CALIOP-ST (CALIOP Science Team) cloud pressure occurrence frequency distributions of the cloud top (dashed line) and for the pressure level inside the cloud when the optical thickness reaches 0.3 (solid line) for West-Sahara (black line) and Hoggar (red line).

\section{Appendix B. Re-Classification of Partially Cloud Covered Pixels}

The occurrence frequency of the SEVIRI partial cloud cover class is between 4 and $6 \%$ in JJAS over the Hoggar and Western Sahara and represents about $21 \%$ of the cloud pixels. To assign a level to these SEVIRI partially cloudy pixels, the same approach as in Dommo et al. [36] is used: each pixel of the partial coverage class is reclassified as high-top, mid-top or low-top cloud depending on the distribution of these three cloud types in the vicinity of the pixel. In this re-classification process, the occurrence frequencies of high-top, mid-top and low-top cloud increase respectively by $1 \%, 1.5 \%$ and $2 \%$. It must be noted that the frequency of partial cloud cover class $(21 \%)$ is low compared to the $67 \%$ of SEVIRI pixels 
where the airborne lidar during the Fennec experiment detects a cloud with a length along the aircraft's trajectory of less than $3 \mathrm{~km}$ [18]. There are two reasons for this, as shown by Kealy et al. [18] using the cloud product retrieved with the Met Office algorithm [78]: (1) when the clouds cover is less than one tenth of the lidar segment passing through the SEVIRI pixel, the pixel is rarely flagged as cloudy and (2) for the pixels considered to be fully covered by SEVIRI, for $30 \%$ of them, there are clear sky holes in the lidar segment. This mixture of clouds and clear sky with a high aerosol load [79] could explain why here, in this study, about $60 \%$ of SEVIRI clouds of medium height are detected as semi-transparent (cirrus in the SAFNWC cloud type classification).

\section{Appendix C. Evaluation of SEVIRI Cloud Classification against CALIOP Light Detection and Ranging (Lidar) Data}

The TOP_LAYER and PASSIVE GEWEX CALIPSO-ST $[77,80]$ data were used for the monthly mean comparison of cloud top pressure distributions (Figure A1b). These mean monthly distributions were derived from version 4 (V4) of the CALIOP Level 2 product [80]. In the TOP_LAYER product, the cloud top pressure distributions are based on the pressure at the top of the highest cloud layer. In the PASSIVE product, to be closer to what can be observed with passive radiometry, the cloud top pressure distributions are constructed from the pressure level inside the clouds where the optical thickness reaches 0.3. From the summer 2009 instantaneous measurements of CALIOP version 3 (V3) [80], comparisons at the pixel level have also been performed. In this comparison the optical thickness of CALIOP cloud layers is limited to greater than 0.1 as in Sèze et al. [33].

As with SEVIRI, the CALIOP-ST cloud top pressure distributions (Figure A1b) show a peak in the mid-troposphere but with a positive bias of $50 \mathrm{hPa}$ to $75 \mathrm{hPa}$. Applying a cloud top pressure calculation method adapted to thin ice clouds, when, the pixel is covered with very fragmented clouds in a dusty environment, could explain this negative bias. In the upper troposphere, in contrast, the peak in the SEVIRI distribution at $275 \mathrm{hPa}$ in June and September is shifted to a lower pressure by about $50 \mathrm{hPa}$. This is in line with what is expected when comparing the cloud top pressure obtained from passive infrared measurements with lidar measurements [81,82]. Between these two peaks, a minimum is observed at $350 \mathrm{hPa}$ as in the SEVIRI distributions. On the side of increasing cloud top pressure from the mid-tropospheric peak, the CALIOP cloud top pressure distribution decreases strongly until $550 \mathrm{hPa}$ to $600 \mathrm{hPa}$ which lies just below the expected altitude of the SABL in summer. These main features of the cloud top pressure distributions are fairly constant across the year in the cloud-top distributions extracted from the GEWEX CALIPSO-ST data set.

When the $350 \mathrm{hPa}$ threshold is used to separate high-top clouds from mid-top clouds, the frequencies of the high-altitude clouds in the SEVIRI data and CALIOP V3 data are very close (Figure A2). At pixel scale, the agreement frequency is 70\% (Figure A2). The main source of disagreement comes from the classification of CALIOP high-top clouds into mi-top clouds in the SEVIRI data set and vice versa. For the mid-top cloud pixels detected by SEVIRI, the match with CALIOP is high ( $82 \%$ to $85 \%$ ), but the occurrence frequency of mid-top cloud is larger for CALIOP than for SEVIRI (bias of $8 \%$ ) (Figure A2). $60 \%$ of CALIOP mid-top cloud and more during the daytime are also classified as fragmented cloud by CALIOP (not shown). This high fraction is in agreement with the results obtained by Kealy et al. [18] with lidar airborne measurements. When the fraction of cloud cover inside the CALIOP segment decreases, the frequency of non detection or detection of a low level cloud by SEVIRI increases. For SEVIRI partial cover included in the mid-top cloud class, CALIOP most frequently also detects a mid-top cloud cover and, less frequently, clear sky (not shown).

The fraction of low-top clouds in the CALIOP V3 data reaches 4\% over Hoggar (Figure A2) and these clouds are most of the time undetected by SEVIRI. In the CALIOP-ST monthly average data, the frequency of low clouds is less than $1 \%$. From version V3 to version V4, the separation between small clouds and dust has been improved [83]. The low clouds 
of CALIOP V3 observed over Western Sahara and Hoggar could in fact be dust. SEVIRI low-top clouds are, in the CALIOP classification, most frequently broken mid-top clouds or (but-less frequently) clear-sky. This is in agreement with the large fraction of re-allocated partial cloud covered pixels belonging to this SEVIRI class. The fraction of CALIOP clear segment is the largest for the SEVIRI pixels which were added to the low cloud class by the re-attribution scheme.

(a)

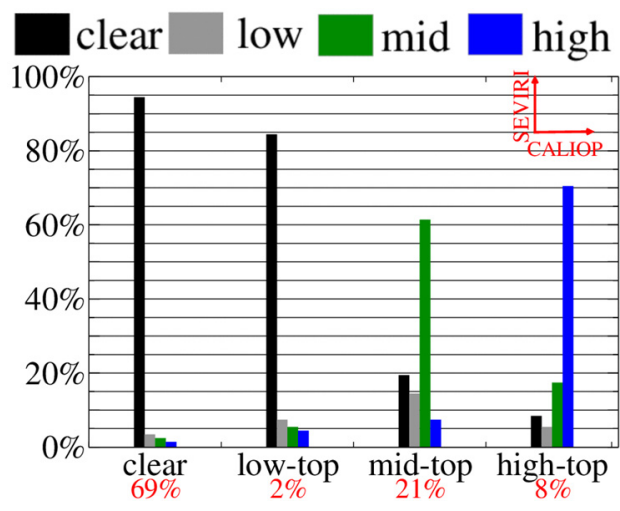

(c)

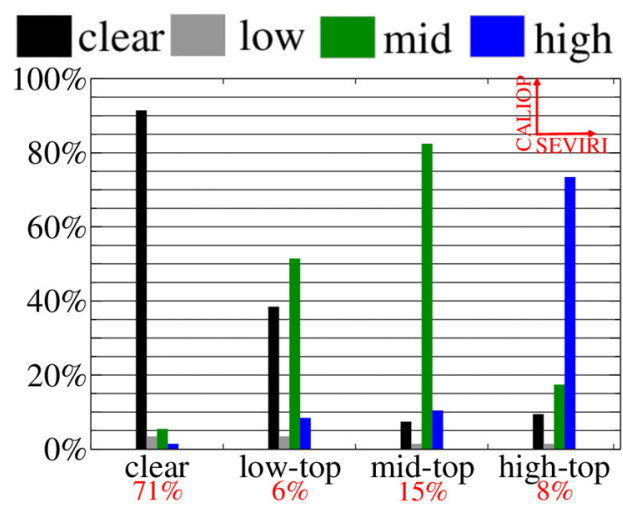

(b)

Hoggar

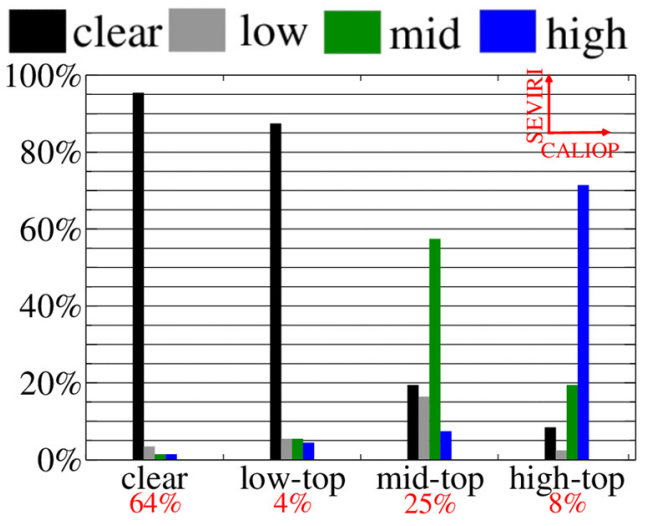

(d)

Hoggar

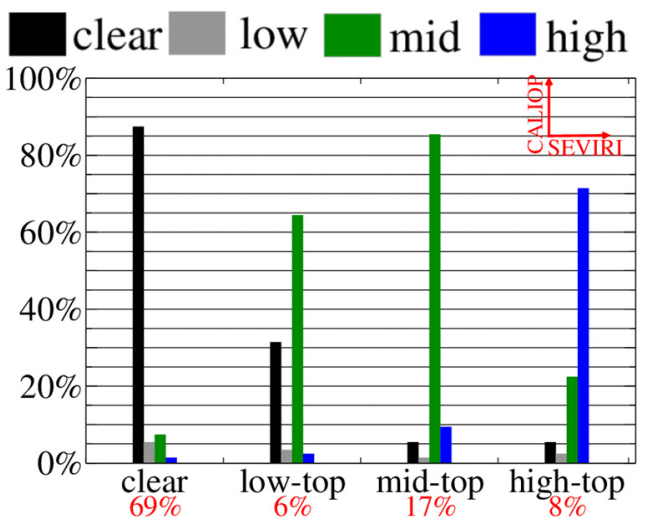

Figure A2. (a,b) Occurrence frequency of the SEVIRI cloud class for each CALIOP cloud class and (c,d) occurrence frequency of the CALIOP cloud class for each SEVIRI cloud class for $(\mathbf{a}, \mathbf{c})$ West-Sahara and $(\mathbf{b}, \mathbf{d})$ Hoggar. The occurrence frequency of each CALIOP $(\mathbf{a}, \mathbf{b})$ and SEVIRI $(\mathbf{c}, \mathbf{d})$ class is also given under the class label on the $X$ axis.

To summarize, this comparison with CALIOP data confirms the choice of a threshold at $350 \mathrm{hPa}$ in order to separate high-top clouds from mid-top clouds. For the separation between mid-top clouds and low-top clouds, a threshold at $550 \mathrm{hPa}$ or $600 \mathrm{hPa}$ would be more appropriate than the $500 \mathrm{hPa}$ chosen here for SEVIRI. The classification used in these results however is not affected by this choice due to (1) the shift towards a lower cloud top pressure of the peak of distribution of mid-top clouds in the SEVIRI data on the Sahara and (2) the absence of low cloud. High clouds are well detected by SEVIRI but some of them are in fact mid-top clouds. The mid-top clouds are not as well detected by SEVIRI. But the clouds detected and attributed to the mid-top cloud class by SEVIRI are indeed mid-top clouds for CALIOP. The frequency of low clouds is very small in the CALIOP data set and they are not detected by SEVIRI. Otherwise, this comparison confirms the results of Kealy et al. [18] obtained from airborne lidar measurements. A very large fraction of the pixels detected cloudy by SEVIRI over the West-Sahara at the top of the SABL are partially covered. Cloud fields determined with SEVIRI are indicative of cloud occurrence frequency at $3 \mathrm{~km}$ scale but not of the total cloud coverage which must be considerably smaller. The 
SEVIRI low clouds including the reallocated partially covered pixels must be considered with caution. They can be very partial mid-top cloud cover but also the product of errors in cloud detection. For these cases for which the radiances must be very close to those of clear sky, detection errors could come from the variability in surface properties or the occurrence of thick dust $[17,79]$.

\section{References}

1. Chauvin, F.; Roehrig, R.; Lafore, J.P. Intraseasonal variability of the Saharan heat low and its link with midlatitudes. J. Clim. 2010, 23, 2544-2561. [CrossRef]

2. Lavaysse, C.; Flamant, C.; Janicot, S.; Knippertz, P. Links between African easterly waves, midlatitude circulation and intraseasonal pulsations of the West African heat low. Q. J. R. Meteorol. Soc. 2010, 136, 141-158. [CrossRef]

3. Janicot, S.; Thorncroft, C.D.; Ali, A.; Asencio, N.; Berry, G.; Bock, O.; Bourlès, B.; Caniaux, G.; Chauvin, F.; Deme, A.; et al. Large-scale overview of the summer monsoon over West Africa during the AMMA field experiment in 2006. Ann. Geophys. 2008, 26, 2569-2595. [CrossRef]

4. Lavaysse, C.; Flamant, C.; Janicot, S.; Parker, D.J.; Lafore, J.P.; Sultan, B.; Pelon, J. Seasonal evolution of the West African heat low: A climatological perspective. Clim. Dyn. 2009, 33, 313-330. [CrossRef]

5. Evan, A.T.; Flamant, C.; Lavaysse, C.; Kocha, C.; Saci, A. Water vapor-forced greenhouse warming over the Sahara Desert and the recent recovery from the Sahelian drought. J. Clim. 2015, 28, 108-123. [CrossRef]

6. Chen, T.C. Maintenance of the midtropospheric North African summer circulation: Saharan high and African easterly jet. J. Clim. 2005, 18, 2943-2962. [CrossRef]

7. Washington, R.; Todd, M.; Middleton, N.J.; Goudie, A.S. Dust-storm source areas determined by the Total Ozone Monitoring Spectrometer and surface observations. Ann. Am. Assoc. Geogr. 2003, 93, 297-313. [CrossRef]

8. Parker, D.J.; Thorncroft, C.D.; Burton, R.R.; Diongue-Niang, A. Analysis of the African easterly jet, using aircraft observations from the JET2000 experiment. Q. J. R. Meteorol. Soc. 2005, 131, 1461-1482. [CrossRef]

9. Cuesta, J.; Dimitri, E.; Mimouni, M.; Flamant, P.H.; Loth, C.; Gibert, F.; Marnas, F.; Bouklila, A.; Kharef, M.; Bouziane, O.; et al. Multiplatform observations of the seasonal evolution of the Saharan atmospheric boundary layer in Tamanrasset, Algeria, in the framework of the African Monsoon Multidisciplinary Analysis field campaign conducted in 2006. J. Geophys. Res. 2008, 113, D00C07. [CrossRef]

10. Messager, C.; Parker, D.; Reitebuch, O.; Agustí-Panareda, A.; Taylor, C.M.; Cuesta, J. Structure and dynamics of the Saharan atmospheric boundary layer during the West African monsoon onset: Observations and analyses from the research flights of 14 and 17 July 2006. Q. J. R. Meteorol. Soc. 2010, 136, 107-124. [CrossRef]

11. Garcia-Carreras, L.; Parker, D.J.; Marsham, J.H.; Rosenberg, P.D.; Brooks, I.M.; Lock, A.P.; Marenco, F.; McQuaid, J.B.; Hobby, M. The turbulent structure and diurnal growth of the Saharan atmospheric boundary layer. J. Atmos. Sci. 2015, 72, 693-713. [CrossRef]

12. Marsham, J.H.; Parker, D.J.; Todd, M.C.; Banks, J.R.; Brindley, H.E.; Garcia-Carreras, L.; Roberts, A.J.; Ryde, C.L. The contrasting roles of water and dust in controlling daily variations in radiative heating of the summertime Saharan heat low. Atmos. Chem. Phys. 2016, 16, 3563-3575. [CrossRef]

13. Roehrig, R.; Bouniol, D.; Guichard, F.; Hourdin, F.; Redelsperger, J.-L. The Present and Future of the West African Monsoon: A Process-Oriented Assessment of CMIP5 Simulations along the AMMA Transect. J. Clim. 2013, 26, 6471-6505. [CrossRef]

14. Thorncroft, C.D.; Parker, D.J.; Burton, R.R.; Diop, M.; Ayers, J.H.; Barjat, H.; Devereau, S.; Diongue, A.; Dumelow, R.; Kindred, D.R.; et al. The JET2000 Project: Aircraft Observations of the African Easterly Jet and African Easterly Waves. Bull. Am. Meteorol. Soc. 2003, 84, 337-351. [CrossRef]

15. Lebel, T.; Cappelaere, C.; Galle, S.; Hanan, N.; Kergoat, L.; Levis, S.; Vieux, B.; Descroix, L.; Gosset, M.; Mougin, E.; et al. AMMA-CATCH studies in the Sahelian region of West-Africa: An overview. J. Hydrol. 2009, 375, 3-13. [CrossRef]

16. Washington, R.; Flamant, C.; Parker, D.; Marsham, J.; McQuaid, J.; Brindley, H.; Todd, M.; Highwood, E.; Ryder, C.; Chaboureau, J.; et al. Fennec-The Saharan Climate System. CLIVAR Exch. 2012, 60, 31-33. Available online: http:/ / www.clivar.org/sites / default/files/documents/Exchanges60.pdf (accessed on 7 February 2021).

17. Marsham, J.H.; Hobby, M.; Allen, C.J.T.; Banks, J.R.; Bart, M.; Brooks, B.J.; Cavazos-Guerra, C.; Engelstaedter, S.; Gascoyne, M.; Lima, A.R.; et al. Meteorology and dust in the central Sahara: Observationsfrom Fennec supersite-1 during the June 2011 Intensive Observation Period. J. Geophys. Res. Atmos. 2013, 118, 4069-4089. [CrossRef]

18. Kealy, J.C.; Marenco, F.; Marsham, J.H.; Garcia-Carreras, L.; Francis, P.N.; Cooke, M.C.; Hocking, J. Clouds over the summertime Sahara: An evaluation of Met Office retrievals from Meteosat Second Generation using airborne remote sensing. Atmos. Chem. Phys. 2017, 17, 5789-5807. [CrossRef]

19. Stein, T.H.; Parker, D.; Delanoë, J.; Dixon, N.; Hogan, R.J.; Knippertz, P.; Maidment, R.; Marsham, J. The vertical cloud structure of the West African monsoon: A 4 year climatology using CloudSat and CALIPSO. J. Geophys. Res. Atmos. 2011, 116, D22205. [CrossRef]

20. Bouniol, D.; Couvreux, F.; Kamsu-Tamo, P.H.; Leplay, M.; Guichard, F.; Favot, F.; O'connor, E.J. Diurnal and seasonal cycles of cloud occurrences, types, and radiative impact over West Africa. J. Appl. Meteorol. Climatol. 2012, 51, 534-553. [CrossRef] 
21. Bourgeois, E.; Bouniol, D.; Couvreux, F.; Guichard, F.; Marsham, J.H.; Carreras, L.G.; Birch, C.E.; Parker, D.J. Characteristics of mid-level clouds over West Africa. Q. J. R. Meteorol. Soc. 2017, 144, 426-442. [CrossRef]

22. Fink, A.H.; Engel, T.; Ermet, V.; Van der Linden, R.; Schneidewind, M.; Redl, R.; Afiesimana, E.; Thiaw, W.; Yorke, C.; Evans, M.; et al. Mean Climate and Seasonnal Cycle. In Meteorology of Tropical West Africa: The Forecasters; Parker, D.J., Diop-Kane, M., Eds.; John Wiley \& Sons Ltd.: Chichester, UK, 2017; pp. 1-39.

23. Roehrig, R.; Chauvin, F.; Lafore, J.P. 10-25-day intraseasonal variability of convection over the Sahel: A role of the Saharan heat low and midlatitudes. J. Clim. 2011, 24, 5863-5878. [CrossRef]

24. Grams, C.M.; Jones, S.C.; Marsham, J.H.; Parker, D.J.; Haywood, J.M.; Heuveline, V. The Atlantic inflow to the Saharan heat low: Observations and modelling. Q. J. R. Meteorol. Soc. 2010, 136, 125-140. [CrossRef]

25. Todd, M.C.; Allen, J.T.C.; Bart, M.; Bechir, M.; Bentefouet, J.; Brooks, B.J.; Cavazos-Guerra, C.; Clovis, T.; Deyane, S.; Dieh, M.; et al. Meteorological and dust aerosol conditions over the western Saharan region observed at Fennec Supersite-2 during the intensive observation period in June 2011. J. Geophys. Res. Atmos. 2013, 118, 8426-8447. [CrossRef]

26. Derrien, M.; Gléau, H.L.; Fernandez, P. Algorithm Theoretical Basis Document for "Cloud Products" (CMa-PGE01 v3.2, CT-PGE02 v2.2 \& CTTH-PGE03 v2.2). SAF/NWC/CDOP2/MFL/SCI /ATBD/01, Issue 3, Rev. 2.1. 2013. Available online: https:/ / www.nwcsaf.org/AemetWebContents/ScientificDocumentation/Documentation/MSG/SAF-NWC-CDOP2-MFLSCI-ATBD-01_v3.2.1.pdf (accessed on 23 March 2021).

27. Derrien, M.; Le Gléau, H. MSG/SEVIRI cloud mask and type from SAFNWC. Int. J. Remote Sens. 2005, 26, 4707-4732. [CrossRef]

28. Derrien, M.; Le Gléau, H. Improvement of cloud detection near sunrise and sunset by temporal-differencing and region-growing techniques with real-time SEVIRI. Int. J. Remote Sens. 2010, 31, 1765-1780. [CrossRef]

29. Saunders, R.W.; Kriebel, K.T. An improved method for detecting clear sky and cloudy radiances from AVHRR data. Int. J. Remote Sens. 1988, 9, 123-150. [CrossRef]

30. Tanre, D.; Deroo, C.; Duhaut, P.; Herman, M.; Morcrette, J.J.; Perbos, J.; Deschamps, P.Y. Description of a computer code to simulate the satellite signal in the solar spectrum: The 5S code. Int. J. Remote Sens. 1990, 11, 659-668. [CrossRef]

31. Schmetz, J.; Holmlund, K.; Hoffman, J.; Strauss, B.; Mason, B.; Gaertner, V.; Kock, A.; DeBerg, L.V. Operational cloud-motion winds from Meteosat infrared images. J. Appl. Meteorol. 1993, 32, 1206-1225. [CrossRef]

32. Menzel, W.P.; Smith, W.L.; Stewart, T.R. Improved cloud motion wind vector and altitude assignment using VAS. J. Appl. Meteorol. 1983, 22, 377-384. [CrossRef]

33. Sèze, G.; Pelon, J.; Derrien, M.; Le Gléau, H.; Six, B. Evaluation against CALIPSO lidar observations of the multigeostationary cloud cover and type dataset assembled in the framework of the Megha-Tropiques mission. Q. J. R. Meteorol. Soc. 2015, 141, 774-797. [CrossRef]

34. Kerdraon, G.; Gléau, H.L. Validation Report for the Cloud Product Processors of the NWC/GEO.NWC/CDOP3/GEO/MFCMS/SCI/VR/Cloud, Issue 1, Rev. 0. 2019. Available online: https:/ / www.nwcsaf.org/Downloads/GEO/2018/Documents/ Scientific_Docs/NWC-CDOP3-GEO-MF-CMS-SCI-VR-Cloud_v1.0.pdf (accessed on 24 March 2021).

35. Hamann, U.; Walther, A.; Baum, B.; Bennartz, R.; Bugliaro, L.; Derrien, M.; Francis, P.N.; Heidinger, A.; Joro, S.; Kniffka, A.; et al. Remote sensing of cloud top pressure/height from SEVIRI: Analysis of ten current retrieval algorithms. Atmos. Meas. Technol. 2014, 7, 2839-2867. [CrossRef]

36. Dommo, A.; Philippon, N.; Seze, G.; Vondou, D.A. The June to September low cloud cover in western Central Africa: Mean diurnal and spatial patterns and associated atmospheric dynamics. J. Clim. 2018, 31, 9585-9603. [CrossRef]

37. Dee, D.P.; Uppala, S.M.; Simmons, A.J.; Berrisford, P.; Poli, P.; Kobayashi, S.; Andrae, U.; Balmaseda, M.A.; Balsamo, G.; Bauer, P.; et al. The ERA-Interim reanalysis: Configuration and performance of the data assimilation system. Q. J. R. Meteorol. Soc. 2011, 137, 553-597. [CrossRef]

38. Parker, D.J.; Burton, R.R.; Diongue-Niang, A.; Ellis, R.J.; Felton, M.; Taylor, C.M.; Thorncroft, C.D.; Bessemoulin, P.; Tompkins, A.M. The diurnal cycle of the West African monsoon circulation. Q. J. R. Meteorol. Soc. 2005, 131, 2839-2860. [CrossRef]

39. Bou Karam, D.; Flamant, C.; Tulet, P.; Chaboureau, J.P.; Dabas, A.; Todd, M.C. Estimate of Sahelian dust emissions in the Intertropical discontinuity region of the West African Monsoon. J. Geophys. Res. 2009, 114, D13106. [CrossRef]

40. Pospichal, B.; Bou Karam, D.; Crewell, S.; Flamant, C.; Hunerbein, A.; Bock, O.; Saîd, F. Diurnal cycle of the intertropical discontinuity over West Africa analysed by remote sensing and mesoscale modeling. Q. J. R. Meteorol. Soc. 2009, 136, 92-106. [CrossRef]

41. Buckle, C. Weather and Climate in Africa; Addison-Wesley Longman Ltd.: Harlow, UK, 1996.

42. Flamant, C.; Chaboureau, J.P.; Parker, D.J.; Taylor, C.M.; Cammas, J.P.; Bock, O.; Timouk, F.; Pelon, J. Airborne observations of the impact of a convective system on the planetary boundary layer thermodynamics and aerosol distribution in the inter-tropical discontinuity region of the West African Monsoon. Q. J. R. Meteorol. Soc. 2007, 133, 1175-1189. [CrossRef]

43. Knippertz, P.; Fink, A.H. Dry-season precipitation in tropical West Africa and its relation to forcing from the extratropics. Mon. Weather Rev. 2008, 136, 3579-3596. [CrossRef]

44. Emmel, C.; Knippertz, P.; Schulz, O. Climatology of convective density currents in the southern foothills of the Atlas Mountains. J. Geophys. Res. 2010, 115, D11115. [CrossRef]

45. Redl, R.; Fink, A.H.; Knippertz, P. An Objective Detection Method for Convective Cold Pool Events and Its Application to Northern Africa. Mon. Weather Rev. 2015, 143, 5055-5072. [CrossRef] 
46. Roberts, A.J.; Marsham, J.H.; Knippertz, P. Disagreements in low-level moisture between (Re)analyses over summertime West Africa. Mon. Weather Rev. 2015, 143, 1193-1211. [CrossRef]

47. Trzeciak, T.M.; Garcia-Carreras, L.; Marsham, J.H. Cross-Saharan transport of water vapor via recycled cold pool outflows from moist convection. Geophys. Res. Lett. 2016, 44, 1554-1563. [CrossRef]

48. Meynadier, R.; Bock, O.; Gervois, S.; Guichard, F.; Redelsperger, J.L.; Agustî̀-Panareda, A.; Beljaars, A. West African Monsoon water cycle: 2. Assessment of numerical weather prediction water budgets. J. Geophys. Res. Atmos. 2010, 115, D19107. [CrossRef]

49. Sultan, B.; Janicot, S. The West African monsoon dynamics. Part II: The "pre-onset" and "onset" of the summer monsoon. J. Clim. 2003, 16, 3407-3427. [CrossRef]

50. Lélé, I.; Leslie, L.M.; Lamb, P. Analysis of Low-Level Atmospheric Moisture Transport Associated with the West African Monsoon. J. Clim. 2015, 28, 4414-4430. [CrossRef]

51. Diedhiou, A.; Janicot, S.; Viltard, A.; De Felice, P.; Laurent, H. Easterly wave regimes and associated convection over West Africa and tropical Atlantic: Results from the NCEP/NCAR and ECMWF reanalyses. Clim. Dyn. 1999, 15, 795-822. [CrossRef]

52. Tyrlis, E.; Lelieveld, J.; Steil, B. The summer circulation over the eastern Mediterranean and the Middle East: Influence of the South Asian monsoon. Clim. Dyn. 2013, 40, 1103-1123. [CrossRef]

53. Knippertz, P.; Fink, A.H.; Reiner, A.; Speth, P. Three late summer/early autumn cases of tropical-extratropical interactions causing precipitation in northwest Africa. Mon. Weather Rev. 2003, 131, 116-135. [CrossRef]

54. Skinner, C.B.; Poulsen, C.J. The role of fall season tropical plumes in enhancing Saharan rainfall during the African Humid Period. Geophys. Res. Lett. 2015, 43, 349-358. [CrossRef]

55. Wu, M.; Reale, O.; Schubert, S.; Suarez, M.; Thorncroft, C. African Easterly Jet: Barotropic Instability, Waves, and Cyclogenesis. J. Clim. 2012, 25, 1489-1510. [CrossRef]

56. Stein, A.F.; Draxler, R.R.; Rolph, G.D.; Stunder, B.J.B.; Cohen, M.D.; Ngan, F. NOAA's HYSPLIT atmospheric transport and dispersion modeling system. Bull. Am. Meteorol. Soc. 2015, 96, 2059-2077. [CrossRef]

57. Holle, R.L.; Simpson, J.; Leavitt, S.W. GATE B-scale cloudiness from whole-sky cameras on four U.S. Ships. Mon. Weather Rev. 1979, 107, 874-895. [CrossRef]

58. Van der Linden, R.; Fink, A.H.; Redl, R. Satellite-based climatology of low-level continental clouds in southern West Africa during the summermonsoon season. J. Geophys. Res. Atmos. 2015, 120, 1186-1201. [CrossRef]

59. Eastman, R.; Warren, S. Diurnal cycles of cumulus, cumulonimbus, stratus, stratocumulus, and fog from surface observations over land and ocean. J. Clim. 2013, 27, 2386-2404. [CrossRef]

60. Dalu, G.A.; Gaetani, M.; Lavaysse, C.; Flamant, C.; Evan, A.T.; Baldi, M. Simple solutions for the summer shallow atmospheric circulation over North Africa. Q. J. R. Meteorol. Soc. 2018, 144, 765-779. [CrossRef]

61. Thorncroft, C.D.; Blackburn, M. Maintenance of the African easterly jet. Q. J. R. Meteorol. Soc. 1999, 125, 763-786. [CrossRef]

62. Knippertz, P. Tropical-extratropical interactions causing precipitation in northwest Africa: Statistical analysis and seasonal variations. Mon. Weather Rev. 2003, 131, 3069-3076. [CrossRef]

63. Knippertz, P.; Martin, J.E. Tropical plumes and extreme precipitation in subtropical and tropical West Africa. Q. J. R. Meteorol. Soc. 2005, 131, 2337-2365. [CrossRef]

64. Fröhlich, L.; Knippertz, P.; Fink, A.H.; Hohberger, E. An objective climatology of tropical plumes. J. Clim. 2013, 24, 5044-5060. [CrossRef]

65. Cornforth, R.; Mumba, Z.; Parker, D.J.; Berry, G.; Chapelon, N.; Diakaria, K.; Diop-Kane, M.; Ermert, V.; Fink, A.H.; Knippertz, P.; et al. Synoptic systems. In Meteorology of Tropical West Africa: The Forecasters; Parker, D.J., Diop-Kane, M., Eds.; John Wiley \& Sons Ltd.: Chichester, UK, 2017; pp. 40-89.

66. Thorncroft, C.D.; Nguyen, H.; Zhang, C.; Peyrillé, P. Annual cycle of the West African monsoon: Regional circulations and associated water vapour transport. Q. J. R. Meteorol. Soc. 2011, 137, 129-147. [CrossRef]

67. Lélé, I.; Lamb, P. Variability of the Intertropical Front (ITF) and Rainfall over the West African Sudan-Sahel Zone. J. Clim. 2010, 23, 3984-4004. [CrossRef]

68. Lavaysse, C.; Eymard, L.; Flamant, C.; Karbou, F.; Mimouni, M.; Saci, A. Monitoring the West African heat low at seasonal and intra-seasonal timescales using AMSU-A sounder. Geophys. Res. Lett. 2013, 14, 263-271. [CrossRef]

69. Couvreux, F.; Guichard, F.; Bock, O.; Campistron, B.; Lafore, J.-P.; Redelsperger, J.L. Synoptic variability of the monsoon flux over West Africa prior to the onset. Q. J. R. Meteorol. Soc. 2010, 136, 159-173. [CrossRef]

70. Cau, P.; Methven, J.; Hoskins, B. Origins of dry air in the tropics and subtropics. J. Clim. 2007, 20, 2745-2759. [CrossRef]

71. Birch, C.E.; Parker, D.J.; Marsham, J.H.; Devine, G.M. The effect of orography and surface albedo on stratification in the summertime Saharan boundary layer: Dynamics and implications for dust transport. J. Geophys. Res. Atmos. 2012, 117, D05105. [CrossRef]

72. Engelstaedter, S.; Washington, R.; Flamant, C.; Parker, D.J.; Allen, C.J.T.; Todd, M.C. The Saharan heat low and moisture transport pathways in the central Sahara-Multiaircraft observations and Africa-LAM evaluation. J. Geophys. Res. Atmos. 2015, 120, 4417-4442. [CrossRef]

73. Vizy, E.K.; Cook, K.H. A mechanism for african monsoon breaks: Mediterranean cold air surges. J. Geophys. Res. Atmos. 2009, 114, D01104. [CrossRef]

74. Redl, R.; Knippertz, P.; Fink, A.H. Weakening and moistening of the summertime Saharan heat low through convective cold pools from the Atlas Mountains. J. Geophys. Res. Atmos. 2016, 121, 3907-3928. [CrossRef] 
75. Gaetani, M.; Fontaine, B.; Roucou, P.; Baldi, M. Influence of the Mediterranean Sea on the West African monsoon: Intraseasonal variability in numerical simulations. J. Geophys. Res. Atmos. 2010, 115, D24115. [CrossRef]

76. Rossow, W.B.; Schiffer, R.A. Advances in understanding clouds from ISCCP. Bull. Am. Meteorol. Soc. 1999, 80, $2261-2287$. [CrossRef]

77. Stubenrauch, C.J.; Rossow, W.B.; Kinne, S.; Ackerman, S.; Cesana, G.; Chepfer, H.; Getzewich, B.; Di Girolamo, L.; Guignard, A.; Heidinger, A.; et al. Assessment of global cloud datasets from satellites: Project and database initiated by the GEWEX radiation panel. Bull. Am. Meteorol. Soc. 2013, 94, 1031-1049. [CrossRef]

78. Hocking, J.; Francis, P.N.; Saunders, R. Cloud detection in Meteosat second generation imagery at the Met Office. Meteorol. Appl. 2011, 18, 307-323. [CrossRef]

79. Banks, J.R.; Brindley, H.E. Evaluation of MSG-SEVIRI mineral dust retrieval products over North Africa and the Middle East. Remote Sens. Environ. 2013, 128, 58-73. [CrossRef]

80. Vaughan, M.; Pitts, M.; Trepte, C.; Winker, D.; Detweiler, P.; Garnier, A.; Getzewich, B.; Hunt, W.; Lambeth, J.; Lee, K.P.; et al. Cloud-Aerosol LIDAR Infrared Pathfinder Satellite Observations: Data Management System-Data Products Catalog, Rev. 4.92. Available online: https://www-calipso.larc.nasa.gov/products/CALIPSO_DPC_Rev4x92.pdf (accessed on 8 February 2021).

81. Holz, R.E.; Ackerman, S.A.; Nagle, F.W.; Frey, R.; Dutcher, S.; Kuehn, R.E.; Vaughan, M.A.; Baum, B. Global Moderate Resolution Imaging Spectroradiometer (MODIS) cloud detection and height evaluation using CALIOP. J. Geophys. Res. Atmos. 2008, 113. [CrossRef]

82. Garnier, A.; Pelon, J.; Dubuisson, P.; Faivre, M.; Chomette, O.; Pascal, N.; Kratz, D.P. Retrieval of cloud properties using CALIPSO imaging infrared radiometer. Part I: Effective emissivity and optical depth. J. Appl. Meteorol. Clim. 2012, 51, 1407-1425. [CrossRef]

83. Liu, Z.; Kar, J.; Zeng, S.; Tackett, J.; Vaughan, M.; Avery, M.; Pelon, J.; Getzewich, B.; Lee, K.-P.; Magill, B.; et al. Discriminating between clouds and aerosols in the CALIOP version 4.1 data products. Atmos. Meas. Technol. 2019, 12, 703-734. [CrossRef] 